\title{
Combined norepinephrine/serotonergic reuptake inhibition: effects on maternal behavior, aggression, and oxytocin in the rat
}

\author{
Elizabeth Thomas Cox ${ }^{1 \dagger}$,Thomas Merryfield Jarrett ${ }^{1,2 \dagger}$, Matthew Stephen McMurray ${ }^{3}$, Kevin Greenhill ${ }^{4}$, \\ Vivian E. Hofler ${ }^{4}$, Sarah Kaye Williams ${ }^{1}$, Paul Wayland Joyner ${ }^{5}$, Christopher L. Middleton ${ }^{6}$, Cheryl H. Walker ${ }^{4}$ \\ and Josephine M. Johns ${ }^{1,3,4}$ *
}

${ }^{1}$ Curriculum in Neurobiology, University of North Carolina at Chapel Hill, Chapel Hill, NC, USA

${ }^{2}$ School of Medicine, University of North Carolina at Chapel Hill, Chapel Hill, NC, USA

${ }^{3}$ Department of Psychology, University of North Carolina at Chapel Hill, Chapel Hill, NC, USA

${ }^{4}$ Department of Psychiatry, University of North Carolina at Chapel Hill, Chapel Hill, NC, USA

${ }^{5}$ Department of Surgery, University of Connecticut, Farmington, CT, USA

${ }^{6}$ Department of Neurosurgery, Medical College of Georgia, Augusta, GA, USA

\section{Edited by:}

Joan Irene Morrell, Rutgers, The State University of New Jersey, USA

\section{Reviewed by:}

Rina Eiden, University at Buffalo, USA

Elizabeth Mccone Byrnes, Tufts

University Cummings School of

Veterinary Medicine, USA

Katharine Seip, The Rockefeller

University, USA

*Correspondence:

Josephine M. Johns, Department of Psychiatry, The University of North

Carolina at Chapel Hill, CB\# 7096,

Chapel Hill, NC 27599-7096, USA.

e-mail: jjohns@med.unc.edu

${ }^{\dagger}$ Elizabeth Thomas Cox and Thomas Merryfield Jarrett have contributed equally to this manuscript as co-first authors.
Background: Few systematic studies exist on the effects of chronic reuptake of monoamine neurotransmitter systems during pregnancy on the regulation of maternal behavior (MB), although many drugs act primarily through one or more of these systems. Previous studies examining fluoxetine and amfonelic acid treatment during gestation on subsequent $\mathrm{MB}$ in rodents indicated significant alterations in postpartum maternal care, aggression, and oxytocin levels. In this study, we extended our studies to include chronic gestational treatment with desipramine or amitriptyline to examine differential effects of reuptake inhibition of norepinephrine and combined noradrenergic and serotonergic systems on $\mathrm{MB}$, aggression, and oxytocin system changes. Methods: Pregnant Sprague-Dawley rats were treated throughout gestation with saline or one of three doses of either desipramine, which has a high affinity for the norepinephrine monoamine transporter, or amitriptyline, an agent with high affinity for both the norepinephrine and serotonin monoamine transporters. MB and postpartum aggression were assessed on postpartum days 1 and 6 respectively. Oxytocin levels were measured in relevant brain regions on postpartum day 7. Predictions were that amitriptyline would decrease $M B$ and increase aggression relative to desipramine, particularly at higher doses. Amygdaloidal oxytocin was expected to decrease with increased aggression. Results: Amitriptyline and desipramine differentially reduced $\mathrm{MB}$, and at higher doses reduced aggressive behavior. Hippocampal oxytocin levels were lower after treatment with either drug but were not correlated with specific behavioral effects. These results, in combination with previous findings following gestational treatment with other selective neurotransmitter reuptake inhibitors, highlight the diverse effects of multiple monoamine systems thought to be involved in maternal care.

Keywords: amitriptyline, desipramine, norepinephrine, serotonin, oxytocin, maternal behavior

\section{INTRODUCTION}

Given the prevalence of pregnant women who use drugs that block neurotransmitter reuptake, such as antidepressants, antianxiety medications, or antipsychotics as well as illegal drugs of abuse (Ritz et al., 1990; Kessler et al., 1994; Cooper et al., 1996; Thomas and Palmiter, 1997), it is surprising to find so little data on the effects of alterations in various neurotransmitter systems on maternal behavior $(\mathrm{MB})$. Depression is among the most prevalent acute and chronic mental health conditions reported by perinatal women (Gaynes et al., 2005) and has been estimated to occur in $8-20 \%$ of women of childbearing age (Weissman et al., 1988; Kessler et al., 1993; Ferro et al., 2000). One study in 2003 estimated that approximately $13 \%$ of women take an antidepressant at some point during their pregnancy (Cooper et al., 2007). Many antidepressants commonly prescribed during pregnancy (Goldberg and Nissim, 1994) differentially act as reuptake inhibitors of norepinephrine (NE), dopamine (DA), and/or serotonin (5-HT) systems (Marek et al., 1988; Porrino et al., 1989; Kessler et al., 1993; Schatzberg, 1998; Bennett et al., 2004; Grover et al., 2006). Therefore, manipulation of neurotransmitter systems in a preclinical model of MB is a potentially useful pharmacological tool to explore their relative contribution to this behavior.

Preclinical models using neurotransmitter reuptake inhibitors during various stages of pregnancy have reported disruptions in MB (Gore, 2001; Johns et al., 2005a,b; Lerch-Haner et al., 2008; Cummings et al., 2010; Strathearn and Mayes, 2010) 
postpartum maternal aggression (MA; Johns et al., 1994; Lonstein and Gammie, 2002) and changes in oxytocin, a neuropeptide known to play an important role in both human and rodent pregnancy, parturition, and subsequent MB (Johns et al., 1997, 2004; Bosch et al., 2005; Feldman et al., 2007; Levine et al., 2007; Neumann, 2008). To date, there is sparse information on the effects of reuptake inhibition of NE or combined NE and 5-HT systems during pregnancy on subsequent measures of MB. In general, central NE depletion and changes in NE metabolism have been associated with disruptions in the onset of MB in rats (Rosenberg et al., 1977; Thomas and Palmiter, 1997). Additionally, studies have found that mice lacking $\mathrm{NE}$ show impaired $\mathrm{MB}$ and that this impairment can be reversed if NE is restored before parturition (Thomas and Palmiter, 1997).

The 5-HT system has been associated with specific components of $\mathrm{MB}$ in animal models, including promotion of lactation, breastfeeding, and oxytocin secretion (Saydoff et al., 1991; Bagdy et al., 1992; Bagdy and Kalogeras, 1993; Uvnas-Moberg et al., 1996; Nissen et al., 1998), whereas reduced 5-HT levels are generally associated with increased aggression (Miczek et al., 2007). Keer and Stern (1999) found that following an intracerebral ventricular infusion of a 5-HT antagonist, crouching behavior in rat dams on postpartum day (PPD) 6 was not disturbed, but when injected into the nucleus accumbens, crouching duration was increased. Johns et al. (2005b) reported that gestational treatment with the 5-HT reuptake inhibitor fluoxetine resulted in strong trends for decreased crouching in dams treated with the high dose compared to controls, and that all doses of fluoxetine treatment increased levels of licking and touching of pups. These same dams also had an increased level of MA toward an intruder on PPD 6, indicating a probable role for $5-\mathrm{HT}$ in pup-directed MB and MA (Johns et al., 2005b).

A single study has investigated the effects of 5-HT reuptake inhibition given during the postpartum period on human maternal-infant interactions. It found that in depressed women, SSRIs can increase maternal gratification (the mother's appreciation of motherhood), but did not improve maternal-infant interactions at 8 weeks postpartum (Logsdon et al., 2009). Although fluoxetine's effect on child abuse in humans has not been examined directly, it has been found to decrease general levels of impulsive aggressive behaviors (Coccaro and Kavoussi, 1997; Coccaro et al., 1997). Yet interestingly, the tricyclic antidepressant amitriptyline, which acts in part by inhibiting 5-HT and NE but not DA reuptake, has been found to increase levels of aggression (Soloff et al., 1986a,b). While these studies were conducted in non-lactational adults with psychiatric conditions, they suggest that the combined reuptake of 5-HT and NE might interact to differentially alter aggression than either 5-HT or NE alone. While NE has been previously associated with increased aggression in humans (Chichinadze et al., 2010) and parallel findings of NE and aggression in animal models have been shown in male rodents (Matsumoto et al., 1995) it is important to note that the few studies that have examined NE-induced alterations in females have shown little association between aggression and NE (Scholtens et al., 1990; Sorensen et al., 2005). This suggests that NE involvement in aggressive behavior is sex specific. There are no published reports, to our knowledge, on NE's role in postpartum aggression. Therefore, combined 5-HT/NE reuptake inhibition could behaviorally manifest itself similarly to what we previously observed following 5-HT alone. With regard to $\mathrm{MB}$, studies suggest NE plays a role in the onset of MB (Rosenberg et al., 1977), while 5-HT-induced changes have been associated more often with active pup-induced MBs, i.e., licking, touching, and crouching over pups (Johns et al., 2005b). Therefore, combined reuptake inhibition could result in greater disruptions in $\mathrm{MB}$ than either alone. However, there are a very limited number of studies that explore behavioral consequences from drug exposure during pregnancy on subsequent MB. It is currently unknown whether reuptake inhibition of the combined 5-HT and NE systems compared to either system individually might differentially alter MB or MA.

Increased oxytocin levels in several brain regions [medial preoptic area (MPOA), ventral tegmental area (VTA), hippocampus, and amygdala] at critical time points during pregnancy or in the postpartum period have been shown to be extremely important in rodent MB and may also play a role in MA. Alterations in the oxytocin system (peptide levels, receptors, and peptide synthesis) in these regions are correlated with abnormalities in $\mathrm{MB}$ and/or MA (Ferris et al., 1992; Bosch et al., 2005; Febo et al., 2005; Neumann, 2009). Of interest to the work presented here, studies suggest that decreased oxytocin levels in the amygdala (Lubin et al., 2003) and the MPOA and VTA (Pedersen et al., 1994; Elliott et al., 2001; Johns et al., 2004) are associated with increased postpartum aggression and deficits in maternal care, respectively. 5-HT receptors have been shown to regulate oxytocin neurons (Sawchenko et al., 1983) and stimulate oxytocin release (Jorgensen et al., 2003), and administration of 5-HT antagonists blocks stress-induced increases in oxytocin secretion (Jorgensen et al., 2002). NE is also an important contributor to the release of oxytocin, speculated to be even more important than 5-HT (Russell et al., 2003; Lipschitz et al., 2004), and NE reuptake inhibitors have been shown to increase hypothalamic oxytocin potency (Bealer and Flynn, 2003). Oxytocin is reduced following gestational treatment with fluoxetine, amfonelic acid, and the combination of both drugs (Johns et al., 2005b). It is unknown if reuptake inhibition of NE, or of both NE and 5-HT, will alter oxytocin at critical periods in the early postpartum period, which could, if true, impact the early maternal environment.

The present study seeks to extend previous findings to determine the effects of gestational treatment with the neurotransmitter reuptake inhibitors amitriptyline (combined 5-HT and NE systems) and desipramine (NE system) on MB using a previously established preclinical model (Johns et al., 2005b). We hypothesized that gestational treatment with amitriptyline and to a lesser degree desipramine alone would decrease $\mathrm{MB}$ resulting from the additive effect of combined neurotransmitter reuptake. Additionally, combined reuptake inhibition was expected to increase MA relative to desipramine treatment alone. Associated increases in aggression were predicted to correlate with decreased oxytocin levels in the amygdala following aggression testing as oxytocin levels have been shown to be inversely correlated with higher aggression levels in this region in previous studies (Lubin et al., 2003). Alternatively, a previous study using combined serotonin and dopamine reuptake inhibitors during gestation resulted in lower levels of oxytocin in the hippocampus associated with somewhat increased 
levels of MA on PPD 6, which implicates this region as one of interest as well (Johns et al., 2005b). Given previous peptide level findings, this study also examined oxytocin levels as opposed to receptors as an initial level of comparison between groups.

\section{MATERIALS AND METHODS SUBJECTS}

Virgin female Sprague-Dawley rats (200-230g) were grouphoused in a temperature and humidity controlled room for a 7-day habituation period prior to breeding. Females were then individually housed with a sexually active male until conception was noted by the presence of a sperm plug. On the day a sperm plug was discovered, designated as gestation day (GD) 0 , the female was removed from the breeding cage, randomly assigned to a treatment group (see below), individually housed, and provided food (Purina Rat Chow) and water ad libitum. Pregnant females were maintained on a reversed 12:12 hour light cycle (lights out at 0900) for 8 days, then transferred to a room with a regular 12:12 hour light cycle (lights on at 0700) for the remainder of the experiment, a procedure that generally results in dams delivering their litters during daylight hours (Mayer and Rosenblatt, 1998).

\section{CHOICE OF DRUGS}

The drugs, amitriptyline and desipramine, were chosen specifically for these studies based on our goals and the attributes of the drugs at the highest doses utilized in this study and following consultation with our pharmacology consultant (Dr. Brian McMillen). With minimal literature available to facilitate even high dose selection (see remainder of this paragraph for review), medium and low doses were chosen relative to high dose for a descending dose response curve. Amitriptyline is a tertiary amine with preference for both the 5-HT and NE transporters, with a half-life in the rat of around $8-12 \mathrm{~h}$. Review of available literature suggests that doses of $10 \mathrm{mg} / \mathrm{kg}$ or less of amitriptyline ensure moderate inhibition of both the 5-HT and NE transporters (Henderson and McMillen, 1993). Amitriptyline's inhibition of both 5-HT and NE transporters are considered comparable in this experimental paradigm because amitriptyline has a similar binding affinity for 5-HT and NE transporters in the adult rat (see Ki column of Table 1), particularly at the likely cerebral spinal fluid concentrations achieved following amitriptyline doses utilized in this study (see CSF column of Table 1). Desipramine, a secondary amine with the greatest known selectivity for the NE transporter, has a half-life of about $8 \mathrm{~h}$ in the rat. Desipramine, when administered to pregnant rats at doses as high as $10 \mathrm{mg} / \mathrm{kg}$, had no overt effect on dam gestational weight gain or number of pups born compared to vehicle injected controls (Montero et al., 1990; Goldberg and Nissim, 1994). Desipramine at the doses used in this study (all less than $7.5 \mathrm{mg} / \mathrm{kg}$ ) will have pharmacokinetic effects (see Table 1 for details) of near total inhibition of the NE transporter and mild to minimal inhibition of the 5-HT transporter (Gould et al., 2006). In addition to their effects as monoamine reuptake inhibitors, both amitriptyline and desipramine function as neuronal sodium and potassium channel blockers when administered in the $\mu \mathrm{M}$ concentration range (Nicholson et al., 2002). Cerebral spinal fluid concentrations of amitriptyline and desipramine achieved in this experiment fall in the $\mathrm{nM}$ concentration range (see Table 1), making blockade of sodium or potassium channels in central nervous system unlikely. At the site of subcutaneous injection, both amitriptyline and desipramine would have been present for short periods of time at $\mu \mathrm{M}$ concentrations. Thus, amitriptyline and desipramine may have functioned as local anesthetics for a period of hours post-injection. All local anesthetic effects would have dissipated by the time of parturition and postpartum behavior testing.

\section{TREATMENT}

The females were randomly assigned to one of seven treatment groups, or as an untreated surrogate. Throughout gestation (GD 1-20), treatment groups received twice daily subcutaneous (SC) injections (on alternating flanks) of either drug (amitriptyline or desipramine) or $0.9 \%$ normal saline for controls in a $1-\mathrm{ml} / \mathrm{kg}$ volume at 9:00 AM, with all control and treatment dams receiving normal saline at $4: 00 \mathrm{PM}(2 \mathrm{ml} / \mathrm{kg}$ total $)$ to match previous treatment regimens used to test MB and MA (Johns et al., 2005b). Amitriptyline treated rats received either a low, medium, or high dose SC injection $(2.5,5$, or $10 \mathrm{mg} / \mathrm{kg}$ respectively) of amitriptyline hydrochloride (Research Biomedicals Inc., Natick, MA, USA) in a $\mathrm{pH} 10$ solution $(0.1 \mathrm{ml} 1 \mathrm{~N} \mathrm{NaOH}$ and $0.6 \mathrm{ml}$ of $0.1 \mathrm{~N} \mathrm{HCl}$ in distilled water) at 9:00 AM. on one flank, followed by their saline injection at 4:00 PM. Desipramine treated rats received either a low, medium, or high dose $(1.25,2.5$, or $5.0 \mathrm{mg} / \mathrm{kg}$

Table 1 | Estimated cerebral spinal fluid concentration by drug dose and reported Ki for individual monoamine transporter proteins.

\begin{tabular}{|c|c|c|c|c|c|c|c|}
\hline \multirow[t]{2}{*}{ Drug } & \multirow[t]{2}{*}{ Dose (mg/kg) } & \multirow[t]{2}{*}{ Plasma (nM) } & \multirow[t]{2}{*}{ Plasma protein binding $(\%)$} & \multirow[t]{2}{*}{ CSF (nM) } & \multicolumn{3}{|c|}{ Ki (nM) } \\
\hline & & & & & 5-HT & NE & DA \\
\hline \multirow[t]{2}{*}{ Amitriptyline } & 8 & 82 & 95 & 4.1 & 84 & 13.9 & 8600 \\
\hline & 15 & 371 & 95 & 18.55 & 84 & 13.9 & 8600 \\
\hline Desipramine & 7.5 & 664 & 90 & 66.4 & 180 & 0.6 & 11000 \\
\hline
\end{tabular}

Table reviewing available literature of studies using: chronic subcutaneous administration, adult rats, drugs of interest at comparable doses to those used in this study, and reported plasma concentrations [8 mg/kg amitriptyline (Brodin et al., 1994), $15 \mathrm{mg} / \mathrm{kg}$ amitriptyline (Benmansour et al., 1999), and 7.5 mg/kg desipramine (Gould et al., 2006)]. Reported cerebrospinal fluid (CSF) concentrations were calculated by multiplying reported drug plasma concentrations and reported plasma protein binding percentages [amitriptyline (Schulz et al., 1985) and desipramine (Sallee and Pollock, 1990)]. Reported Ki values for serotonin (5-HT), norepinephrine (NE), and dopamine (DA) transport proteins are for rat synaptosomes (Bolden-Watson and Richelson, 1993). 
respectively) of desipramine hydrochloride at 9:00 AM and saline at 4:00 PM. Single rather than twice daily doses of amitriptyline and desipramine were also given because of the long half-life (Ghose, 1980) of these drugs and to match previous studies (Johns et al., 2005b). Twice daily injections given on alternate flanks have been shown to minimize skin trauma from injections, although we saw no significant evidence of skin trauma with amitriptyline as we have seen in previous studies using either cocaine or fluoxetine treatment (Johns et al., 2005b).

Weight gain was recorded daily except for surrogate dams. Surrogate dams received no treatment other than handling and were weighed every 5 days. All treatment dams received eight age matched male pups from a surrogate dam within $12 \mathrm{~h}$ of parturition. All procedures were conducted under an approved protocol using federal and University Institutional Animal Care and Use Committee guidelines for humane treatment of laboratory subjects.

\section{MATERNAL BEHAVIOR TESTING}

Upon delivery of their last pup, designated as PPD 1, the dams were brought in their home cage to a $10 \times 12 \mathrm{ft}$. observation room. Dam and pups were not brought to the test room until all pups had delivered, been cleaned and all had milk bands showing they had nursed. This treatment regimen has been used in a number of past studies (Johns et al., 1994; Lonstein and Gammie, 2002) since a primary interest of this work is in the onset of $\mathrm{MB}$ when oxytocin is most relevant. Dams and their litters were brought to the test chamber for habituation only after they have cleaned all pups and pups have milk bands. Since dams had time to clean and feed their pups before they were separated, an essential element for maternal response, we do not feel pup separation on PPD 1 disrupted MB. Pilot work showed when pups are removed immediately after birth and mothers are not given time to clean or feed pups overall $\mathrm{MB}$ is reduced but this is not the case with this paradigm. The home cage was placed into a $24 \times 16 \times 20$ in. dimly lit testing cubicle, designed to reduce environmental distractions during testing, and the subject's pups were removed. Gestational weight gain and length, litter size and weight, and gender of pups were recorded. Eight male surrogate pups born within $12 \mathrm{~h}$ of a test dam's delivery were placed in a warm cage above the test cubicles while the dam to be tested habituated to the room for $30 \mathrm{~min}$. After the habituation period, 10 pieces of nesting material (paper towel strips) were placed at the rear of the cage and the eight male surrogate pups were placed in the front of the cage. Surrogate pups were used to control for any confounds of pup behavioral differences related to prenatal drug exposure that might affect maternal care. Cross fostering at this time point has been shown in a number of previous studies in our laboratory to have no deleterious effects on maternal acceptance of offspring, given that all mothers have nursed and cleaned their own litters and pups are readily accepted and cared for (Johns et al., 2005b). Untreated male surrogate pups were used to eliminate the possible effects of differential pup treatment due to gender preference, which has sometimes been reported (Hahn and Lavooy, 2005), we have seen little evidence of this in past testing with other drug treatment paradigms (Johns et al., 2005b). MB was tested on PPD 1 both to compare to previous studies and because we were most interested in the early onset of $\mathrm{MB}$, which is most dependent on oxytocin system related changes. Videotaping with a VHS recorder with low light sensitivity began as soon as the pups were placed into the cage and continued for $30 \mathrm{~min}$. All pups were observed for any physical danger from the dam during testing. Typical MBs of interest in our lab, which have been previously described (Johns et al., 1994), focus primarily on activity and pup-directed behavior displayed by the dam. These include: nestbuild (dam manipulates paper strips with her mouth or paws); touch/sniff pups (dam touches pups with her front paws or nose); retrieve pups (dam retrieves two, six or eight pups from the front to the back of the cage); self-groom (dam grooms herself with her tongue or paws); rest off/lie on (dam rests away from the pups or lies flat on top of pups); crouch (dam stands over the pups with her back arched in the nursing position with stiff straight legs and head lowered); lick pups (dam licks the pups); rear/sniff (dam rears and sniffs the cage or air); and other (any behavior other than those designated above including locomotor activity). Following $\mathrm{MB}$ testing, dams and their surrogate litters were returned to the colony and monitored daily to assure pup health. This model used to study rodent maternal neglect has been employed successfully in previous studies following gestational drug treatment (Henderson and McMillen, 1993).

\section{POSTPARTUM AGGRESSION TESTING}

On PPD 6, dams and their litters were brought in their home cage to the behavioral observation room where pups and dams were weighed. PPD 6 was chosen for the study of MA testing to match previous studies which show that drug related changes have peak effects on MA on this day (Johns et al., 2005b). Additionally, oxytocin system changes in the amygdala are particularly associated with behavioral increases in aggressive behavior by PPD 6. Dams and litters were then returned to their home cages which were then placed in the testing cubicle for a 5 min chamber habituation period. Following the habituation period, a smaller male intruder $(175 \mathrm{~g})$ was placed in the cage on the end opposite the dam and her litter, and the session was videotaped for a 10 -min period. The sessions were closely observed for danger to the pups, male intruder, or dam, and if harm appeared imminent then the session was stopped and data from that session was excluded from the statistical analysis. A new male was used for each test so that previous experience of the intruder would not affect their behavior. Following testing, the male was removed from the cage, and the dam and pups were returned to the colony room. The behaviors of interest for postpartum aggression have been previously described (Lubin et al., 2003), and include: push/box/kick (dam pushes or kicks the intruder); MB (dam licks pups, retrieves, or crouches over pups); rough groom (dam grooms intruder male roughly, usually around head, neck, or back); self-groom (dam grooms herself); lateral/front threat (dam threatens male while approaching laterally, or face to face); fight attack (a quick lunge by the female usually followed by rolling, biting, and fur pulling directed toward the neck and back regions of the intruder); rear/sniff (dam rears on hind legs and sniffs the top or sides of cage); nip/bite (dam nips or bites male but not in a fight attack); chase male (female chases intruder); aggressive posture (dam stands over a submissive intruder with extended front paws pressing down on him); and 
other (any behavior other than those included in the categories above).

\section{BRAIN DISSECTION}

On PPD 7, at approximately 9:00 AM, 1 day following postpartum aggression testing, dams were killed by decapitation. The brain was removed and the whole MPOA, hippocampus, amygdala, and VTA were dissected on ice, weighed, and rapidly frozen and stored at $-80^{\circ} \mathrm{C}$ for later oxytocin radioimmunoassay as previously described (Johns et al., 1997). Brains were coronally sectioned from the ventral side rostral to the optic chiasm, approximately A7100 (Konig and Klippel, 1963), and just caudal to the optic chiasm, approximately A5800 (Konig and Klippel, 1963), to define the preoptic-anterior hypothalamic area. The MPOA was dissected by making a horizontal cut ventral to the anterior commissure and vertical cuts inferior to the lines of lateral ventricles. The brains were sectioned once again just caudal to the tuber cinereum, approximately A3800 (Konig and Klippel, 1963), to define the medial basal hypothalamus. The amygdala was removed from these two sections. The VTA was dissected from the caudal section by making dorso-ventral cuts medial to the optic tracts with a dorsal cut at the ventral extent of the central gray and the whole hippocampus was then removed from the caudal remainder of the brain.

\section{OXYTOCIN RADIOIMMUNOASSAY}

Brain region tissues were homogenized in cold buffer $(19 \mathrm{mM}$ monobasic sodium phosphate, $81 \mathrm{mM}$ dibasic sodium phosphate, $0.05 \mathrm{M} \mathrm{NaCl}, 0.1 \% \mathrm{BSA}, 0.1 \%$ Triton $100,0.1 \%$ sodium azide, $\mathrm{pH}$ 7.4 ) and centrifuged at $3000 \times g$ for $30 \mathrm{~min}$. Oxytocin immunoreactive content was assayed in the supernatant according to a protocol from Peninsula Labs (Belmont, CA, USA). Samples and standards (1.0-128.0 pg) were incubated in duplicate for 16-24 h at $4^{\circ} \mathrm{C}$ with rabbit anti-oxytocin serum. They were then incubated for $16-24 \mathrm{~h}$ at $4^{\circ} \mathrm{C}$ with ${ }^{125} \mathrm{I}$-oxytocin after which time normal rabbit serum and goat anti-rabbit IgG serum were added and incubated $90 \mathrm{~min}$ at room temperature. The ${ }^{125} \mathrm{I}$-oxytocin bound to the antibody complex was separated from free by a 30-min centrifugation at $4^{\circ} \mathrm{C}$. The radioactivity in the pellet was measured using a LKB CliniGamma counter, which calculates the picogram content of oxytocin in each sample from the standard curve.

\section{DATA ANALYSES}

Taped sessions were scored by two independent observers blind to treatment condition with inter-and intra-reliability set at $90 \%$ or better concurrence for frequency and latency, and $80 \%$ or better for duration of behaviors displayed by the dam. No sessions had to be excluded for physical danger to the pups during testing for MB or MA. A computer program calculated the frequency, duration, latency, and sequence of all relevant behaviors displayed by the rat dams. If a particular behavior of interest was not exhibited by a dam, she was assigned a frequency and duration of 0 , and the highest possible latency for the behavior (1800 s for $\mathrm{MB}$, and $600 \mathrm{~s}$ for MA). Weighted additive models for time to event best fit the duration data analyzed from the MB dataset as well as the oxytocin and gestational datasets. Log linear models for count data fit the frequency data analyzed from the postpartum aggression dataset best. These models were used to examine within drug group differences (high, medium, low dose) as well as between drug group differences (amitriptyline, desipramine, saline) in all datasets.

Considering the large number of observations made for $\mathrm{MB}$ and postpartum aggression for each dam, general estimating methods were used to obtain group estimates and standard errors. Additionally $p$-values were adjusted for multiple comparisons via the FDR method (Benjamini et al., 2001). Only measures we felt most relevant to our specific hypotheses were chosen a priori, for group comparison for both MB (duration of touch, crouch, lick) and a composite measure of activity (combined categories of other and rear/sniff) and for postpartum aggression (frequency of threat, fight attack, and aggressive posture). Using the Pearson product-moment correlation coefficient, there were no significant direct correlations between oxytocin levels on PPD 7 and aggression measures on PPD 6, thus comparisons of oxytocin levels (picograms/mg) were made between all groups for all four brain regions. Estimates of the means and standard errors under the model are presented graphically for frequency and duration data. Statistical significance was set at the $p \leq 0.05$ level. Results are significant unless otherwise stated and are presented in the text under relevant subheadings and reported first within each drug (amitriptyline-A, desipramine-D), at each treatment level (high- $\mathrm{H}$, medium-M, low-L), between drug treatment and control treatment (saline) dam groups, and lastly between corresponding drug treatment groups (for example, amitriptyline high dose treatment vs. desipramine high dose treatment). Statistically significant results directly relevant to hypotheses are described in text, with details of all statistical comparisons and individual significance levels contained in relevant figures and legends. Groups are designated by abbreviations of their respective drug or control (amitriptyline/desipramine/saline) groups, followed by letters (see above) indicating dose level. For example, desipramine low dose treatment dams would be labeled as DL.

\section{RESULTS}

\section{GESTATION VARIABLES}

Dam test numbers are noted in Table 2 with the exception of a lower number of MB dams coded in the $\mathrm{AH}$ (7 total) and DM (9 total) dam groups compared to those coded for postpartum aggression testing, brain oxytocin level measurement, and gestational variables. This was the result of VHS tape failure during recording or playback of $\mathrm{MB}$ testing sessions for these animals. Though no MB data was available for those particular dams, they all completed $\mathrm{MB}$ testing so their data were included for remaining assessments of postpartum aggression, brain oxytocin levels, and gestational variables.

\section{Amitriptyline}

There were no significant differences within or between amitriptyline treatment and saline control groups on the measures of gestation length, gestational weight gain, or birth litter size (see Table 2). AL dams' weight on gestational day 0 was significantly higher than both AM dams $\left[\chi^{2}{ }_{(1)}=6.85, p \leq 0.01\right]$ and saline control dams $\left[\chi^{2}{ }_{(1)}=4.24, p \leq 0.05\right]$. AH birth litters weighed less on PPD 1 than $\mathrm{AL}\left[\chi^{2}{ }_{(1)}=4.91, p \leq 0.05\right]$, however average individual $\mathrm{AH}$ pup weight did not differ (litter weight divided by 
Table 2 | Gestational variables.

\begin{tabular}{lllllllll}
\hline Drug & $\begin{array}{l}\text { Number } \\
\text { tested } \\
\text { (\# dams) }\end{array}$ & $\begin{array}{l}\text { Gestational } \\
\text { length } \\
\text { (days) }\end{array}$ & $\begin{array}{l}\text { Dam } \\
\text { weight } \\
\text { gain (g) }\end{array}$ & $\begin{array}{l}\text { Litter } \\
\text { weight on } \\
\text { PPD 1 (g) }\end{array}$ & $\begin{array}{l}\text { Average } \\
\text { birth } \\
\text { litter size } \\
\text { (\# pups) }\end{array}$ & $\begin{array}{l}\text { Average } \\
\text { PPD 1 pup } \\
\text { weight } \\
\text { (g/pup) }\end{array}$ & $\begin{array}{l}\text { Surrogate litter } \\
\text { weight } \\
\text { PPD 1 (g) }\end{array}$ & $\begin{array}{l}\text { Surrogate litter } \\
\text { weight gain } \\
\text { PPD 1-6 (g) }\end{array}$ \\
\hline AH & $11 *$ & $21.0 \pm 0.14$ & $132.27 \pm 5.51$ & $78.82 \pm 4.50 /$ & $12.55 \pm 0.80$ & $6.31 \pm 0.14$ & $47.64 \pm 2.08 M, S, d$ & $41.45 \pm 2.94 M, L, S, d$ \\
AM & 7 & $21.0 \pm 0.18$ & $146.57 \pm 6.92$ & $81.43 \pm 5.64$ & $12.86 \pm 1.00$ & $6.32 \pm 0.18$ & $59.71 \pm 2.60 /$ & $60.43 \pm 3.69$ \\
AL & 9 & $21.0 \pm 0.16$ & $137.33 \pm 6.10$ & $93.67 \pm 4.97$ & $14.78 \pm 0.88$ & $6.37 \pm 0.15$ & $50.33 \pm 2.30 s$ & $53.67 \pm 3.25$ \\
Saline & 9 & $21.0 \pm 0.15$ & $147.11 \pm 6.10$ & $89.67 \pm 4.97$ & $14.11 \pm 0.88$ & $6.42 \pm 0.15$ & $58.11 \pm 2.30$ & $60.78 \pm 3.25$ \\
DH & 11 & $20.91 \pm 0.14$ & $142.45 \pm 5.52$ & $81.73 \pm 4.50$ & $14.00 \pm 0.80$ & $5.85 \pm 0.14 S, a$ & $57.18 \pm 2.08$ & $52.45 \pm 2.94 a$ \\
DM & $11 *$ & $20.64 \pm 0.14$ & $130.27 \pm 5.52 s$ & $75.27 \pm 4.50 s$ & $13.09 \pm 0.80$ & $5.78 \pm 0.14 S, a$ & $56.73 \pm 2.08$ & $52.45 \pm 2.94$ \\
DL & 11 & $21.00 \pm 0.14$ & $140.00 \pm 5.52$ & $83.00 \pm 4.50$ & $13.91 \pm 0.88$ & $6.08 \pm 0.14$ & $53.45 \pm 2.08$ & $51.45 \pm 2.94 s$
\end{tabular}

Mean \pm SEM of all gestational measures. Group means designated with an italicized lower case letters are statistically significant at $p \leq 0.05$, italicized CAPITAL letters are significant at the $p \leq 0.01 . h, m$, and I denotes a significant difference between high, medium, and low dose groups within a drug treatment group. An s denotes significant differences between drug treatment group and saline control; a denotes statistical difference for a desipramine group from corresponding amitriptyline treatment group; and a d for a amitriptyline group from corresponding desipramine treatment group. By corresponding treatment group authors mean that high, medium, and low doses in the amitriptyline groups were compared to the same relative doses (i.e., high, medium, low) in the desipramine groups. AH, amitriptyline high group (10 mg/kg); $A M$, amitriptyline medium (5 mg/kg); $A$ L, amitriptyline low $(2.5 \mathrm{mg} / \mathrm{kg}) ; D H$, desipramine high $(5 \mathrm{mg} / \mathrm{kg}) ; \mathrm{DM}$, desipramine medium (5 mg/kg); $D L$, desipramine low $(1.25 \mathrm{mg} / \mathrm{kg})$; Saline $(2 \mathrm{~m} / \mathrm{kg})$. *The number of coded observations of $M B$ was reduced in the DH and DM groups as stated in the Section "Results."

litter number) at this time, suggesting this is an effect of slight differences in litter number (not significantly different) rather than individual pup size. On PPD 1, AH surrogate litters weighed less than surrogate litters of $\mathrm{AM}\left[\chi^{2}(1)=13.15, p \leq 0.01\right]$ and saline control litters $\left[\chi^{2}(1)=11.45, p \leq 0.01\right]$. Surrogate litters of $\mathrm{AH}$ dams gained significantly less over PPDs $1-6$ than did those of $\operatorname{AM}\left[\chi^{2}{ }_{(1)}=16.16, p \leq 0.01\right], \operatorname{AL}\left[\chi^{2}{ }_{(1)}=7.75, p \leq 0.01\right]$ or saline control litters $\left[\chi^{2}(1)=19.40, p \leq 0.01\right]$.

\section{Desipramine}

There were no significant differences within any desipramine treated or between desipramine and saline dams on gestation length, birth litter size, or PPD 1 surrogate litter weight. DM dams gained less weight across gestation (GD 1-20) than did saline dams $\left[\chi^{2}(1)=4.19, p \leq 0.05\right.$, see Table 2]. DL dams' weight on GD 0 was significantly higher than both $\mathrm{DH}\left[\chi^{2}{ }_{(1)}=4.75, p \leq 0.05\right]$ and saline control $\left[\chi^{2}{ }_{(1)}=8.78, p \leq 0.01\right]$ dams. The average individual pup weight of DH litters on PPD 1 was lower than saline controls $\left[\chi^{2}(1)=7.66, p \leq 0.01\right]$. DM litters had a lower litter birth weight $\left[\chi^{2}(1)=4.61, p \leq 0.05\right]$ and individual pup birth weight $\left[\chi^{2}(1)=9.42, p \leq 0.01\right]$ than did litters born to saline dams.

\section{Amitriptyline vs. desipramine}

As illustrated in Table 2, AH surrogate litters gained less weight over PPDs $1-6$, than did DH litters $\left[\chi^{2}(1)=6.98, p \leq 0.01\right]$. AM dams weighed less on GD 0 than DM dams $\left[\chi^{2}(1)=5.17\right.$, $p \leq 0.05]$. AH and AM birth litters had higher average individual pup weights on PPD 1 than $\mathrm{DH}\left[\chi^{2}(1)=5.62, p \leq 0.05\right]$ and DM $\left[\chi^{2}(1)=5.75, p \leq 0.05\right]$ litters, respectively.

\section{MATERNAL BEHAVIOR Amitriptyline}

There were significant within treatment dose effects with amitriptyline groups and between amitriptyline and saline control groups on all measures of MB analyzed (see Figure 1). AH dams crouched for a shorter duration than all other amitriptyline dams $\mathrm{AM}\left[\chi^{2}{ }_{(1)}=17.69, p \leq 0.01\right]$; $\mathrm{AL}\left[\chi^{2}{ }_{(1)}=15.26, p \leq 0.01\right]$ or saline controls $\left[\chi_{(1)}^{2}=20.81, p \leq 0.01\right]$. Interestingly, the $\mathrm{AH}$ dams touched pups more $\mathrm{AM}\left[\chi^{2}{ }_{(1)}=13.77, p \leq 0.01\right]$; $\mathrm{AL} \quad\left[\chi^{2}(1)=12.89, p \leq 0.01\right]$; saline controls $\left[\chi^{2}(1)=8.13\right.$, $p \leq 0.01]$ and also licked them longer than other dams AM $\left[\chi^{2}{ }_{(1)}=17.14, p \leq 0.01\right] ; \mathrm{AL}\left[\chi^{2}{ }_{(1)}=18.91, p \leq 0.01\right]$; saline controls $\left[\chi^{2}(1)=18.88, p \leq 0.01\right]$. Finally, AH dams were generally more active than other dams $\operatorname{AM}\left[\chi^{2}{ }_{(1)}=19.65, p \leq 0.01\right]$; $\mathrm{AL}\left[\chi^{2}{ }_{(1)}=11.45, p \leq 0.01\right]$; and saline controls $\left[\chi^{2}(1)=24.63\right.$, $p \leq 0.01]$, as shown in Figure 1.

\section{Desipramine}

$\mathrm{DH}\left[\chi^{2}{ }_{(1)}=3.94, p \leq 0.05\right]$ and $\mathrm{DM}\left[\chi^{2}{ }_{(1)}=6.05, p \leq 0.05\right] \mathrm{dams}$ crouched less than did saline treated dams, as shown in Figure 2. The DM dams were more active $\left[\chi^{2}(1)=4.60, p \leq 0.05\right]$ than were the saline controls. There were no other statistically significant between group differences on MB measures in desipramine or saline control dams.

\section{Amitriptyline vs. desipramine}

AH dams crouched over pups for a shorter duration $\left[\chi^{2}{ }_{(1)}=8.47\right.$, $p \leq 0.01]$ but touched $\left[\chi_{(1)}^{2}=7.77, p \leq 0.01\right]$ and licked $\left[\chi^{2}{ }_{(1)}=19.53, p \leq 0.01\right]$ pups longer than did the DH dams (see Figure 3). AH dams were also more active $\left[\chi^{2}{ }_{(1)}=19.95, p \leq 0.01\right]$ than were DH dams in general. Conversely, AM dams crouched longer than did DM $\left[\chi^{2}(1)=4.84, p \leq 0.05\right]$ dams while DM and DL dams touched pups longer than did AM $\left[\chi^{2}(1)=5.31\right.$, $p \leq 0.05]$ or $\mathrm{AL}\left[\chi^{2}(1)=5.49, p \leq 0.05\right]$ dams.

\section{POSTPARTUM AGGRESSION Amitriptyline}

As shown in Figure 4, AH dams attacked intruders less saline controls $\left[\chi^{2}{ }_{(1)}=5.26, p \leq 0.05\right]$, had a higher frequency of aggressive postures aggressive posture $\mathrm{AL}$ only $\left[\chi^{2}{ }_{(1)}=5.63, p \leq 0.05\right]$ 

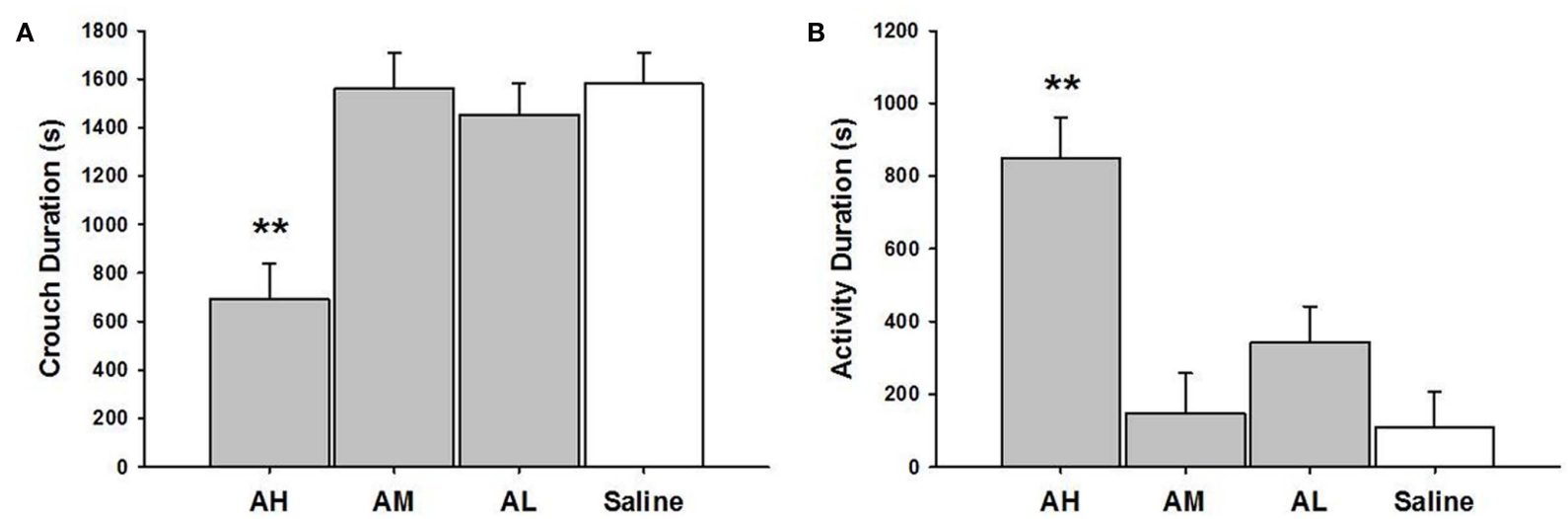

C
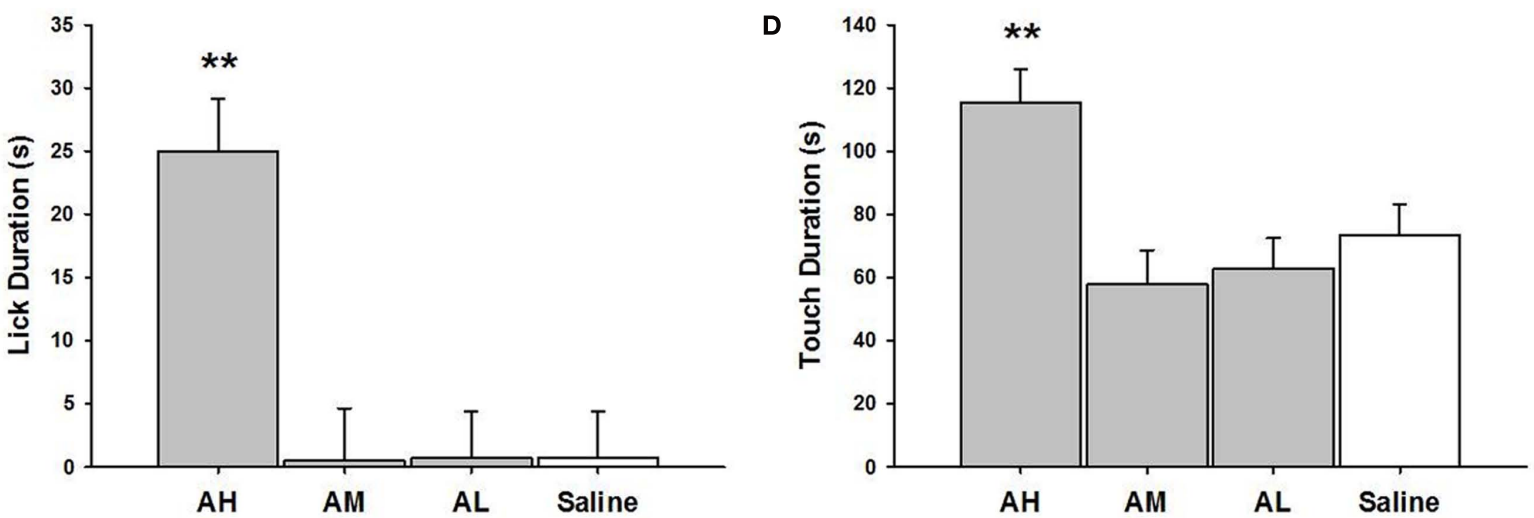

FIGURE 1 | Mean \pm SEM of all MB measures organized in four panels of bar charts for all amitriptyline groups. Each panel is for a specific behavior [(A) Crouch; (B) Activity; (C) Lick; (D) Touch]. All four panels measure duration in seconds (s) on the $Y$ axis and $X$ axis includes categories for all amitriptyline

groups and saline controls. Gray bars denote amytriptyline groups [AH, amitriptyline high (10 mg/kg); AM, amitriptyline medium $(5 \mathrm{mg} / \mathrm{kg}) ; \mathrm{AL}$, amitriptyline low $(2.5 \mathrm{mg} / \mathrm{kg})]$. While bars denote saline control group [Saline $=$ normal saline $(2 \mathrm{ml} / \mathrm{kg})]$. ${ }^{*} p \leq 0.05 ;{ }^{*} p \leq 0.01$.
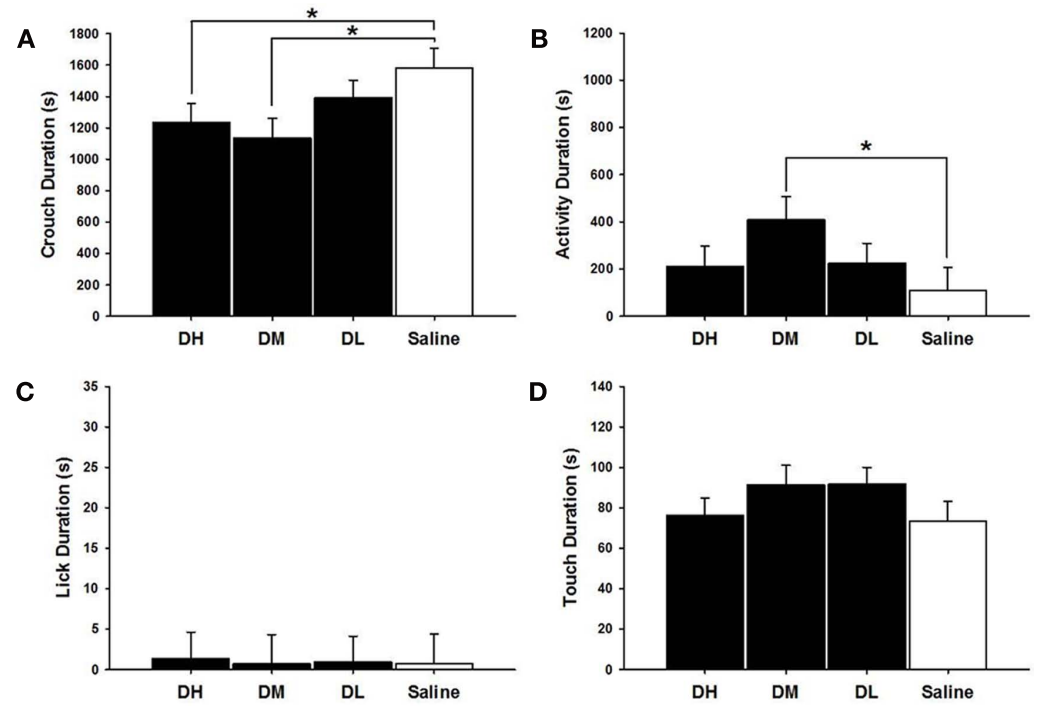

FIGURE 2 | Mean \pm SEM of all MB measures organized in four panels of bar charts for all desipramine groups. Each panel is for a specific behavior [(A) Crouch; (B) Activity; (C) Lick; (D) Touch]. All four panels measure duration in seconds (s) on the $Y$ axis and $X$ axis includes categories for all desipramine

groups and saline controls. Black bars denote desipramine groups [DH, desipramine high $(5 \mathrm{mg} / \mathrm{kg})$; DM, desipramine medium $(2.5 \mathrm{mg} / \mathrm{kg}) ; \mathrm{DL}$, desipramine low $(1.25 \mathrm{mg} / \mathrm{kg})$ ]. While bars denote saline control group [Saline $=$ normal saline $(2 \mathrm{ml} / \mathrm{kg})] .{ }^{*} p \leq 0.05 ;{ }^{*} p \leq 0.01$. 
A

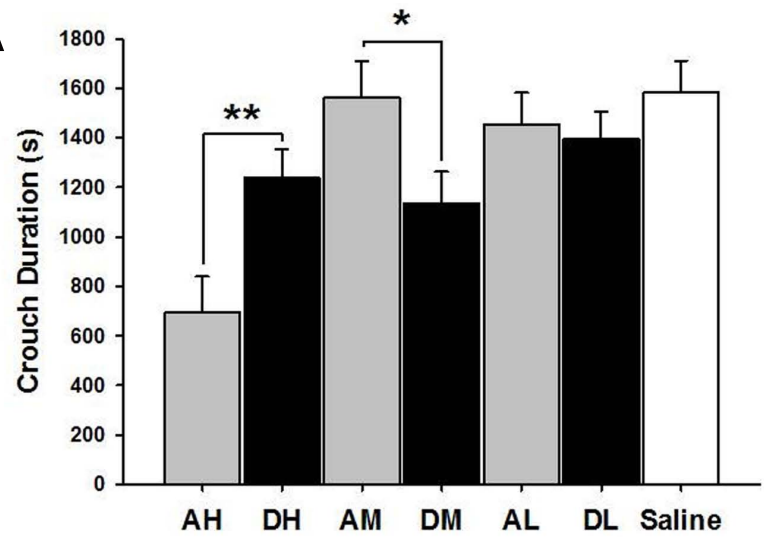

C

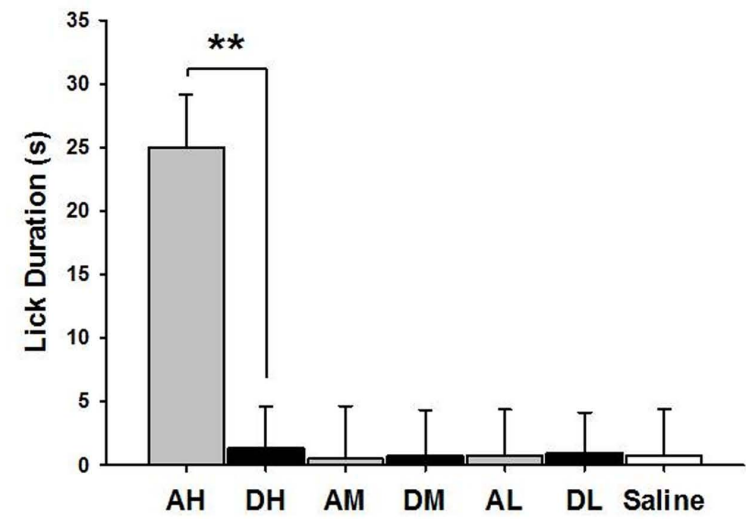

FIGURE 3 | Mean \pm SEM of all MB measures organized in four panels of bar charts by behavior for all amitriptyline and desipramine groups. Each panel is for a specific behavior [(A) Crouch; (B) Activity; (C) Lick;

(D) Touch]. All four panels measure duration in seconds (s) on the $Y$ axis and $X$ axis includes categories for all amitriptyline groups in gray [AH,

amitriptyline high group $(10 \mathrm{mg} / \mathrm{kg})$; $A M$, amitriptyline medium $(5 \mathrm{mg} / \mathrm{kg}) ; A L$, amitriptyline low $(2.5 \mathrm{mg} / \mathrm{kg})]$, all desipramine groups in black [DH,

and threatened intruders less than other dam groups all dams, $\mathrm{AM}\left[\chi^{2}(1)=14.84, p \leq 0.01\right] ; \mathrm{AL}\left[\chi^{2}{ }_{(1)}=50.16, p \leq 0.01\right]$; and saline controls $\left[\chi^{2}(1)=16.03, p \leq 0.01\right]$. AL dams threaten intruders more than $\mathrm{AM}\left[\chi^{2}(1)=6.29, p \leq 0.05\right]$ or saline treated dams $\left[\chi^{2}(1)=9.48, p \leq 0.05\right]$.

\section{Desipramine}

As shown in Figure 4, all desipramine dams threatened intruders less than saline treated dams DH $\left[\chi^{2}{ }_{(1)}=40.36, p \leq 0.01\right]$; $\mathrm{DM}\left[\chi^{2}{ }_{(1)}=31.52, p \leq 0.01\right]$; and DL $\left[\chi^{2}(1)=24.71, p \leq 0.01\right]$. $\mathrm{DH}$ treated dams also attacked intruders less DM $\left[\chi^{2}{ }_{(1)}=11.18\right.$, $p \leq 0.01]$; saline controls $\left[\chi^{2}{ }_{(1)}=16.47, p \leq 0.01\right]$, and were less likely to pin intruders with an aggressive posture than were other dam groups $\mathrm{DM}\left[\chi^{2}{ }_{(1)}=4.13, p \leq 0.05\right]$; $\mathrm{DL}\left[\chi^{2}{ }_{(1)}=6.09\right.$, $p \leq 0.05]$; saline controls $\left[\chi^{2}{ }_{(1)}=7.46, p \leq 0.01\right]$. DL dams attacked intruders less often than did saline treated dams $\left[\chi^{2}(1)=6.33, p \leq 0.05\right]$.

\section{Amitriptyline vs. desipramine}

All doses of amitriptyline significantly increased the frequency of threat when compared to their corresponding high
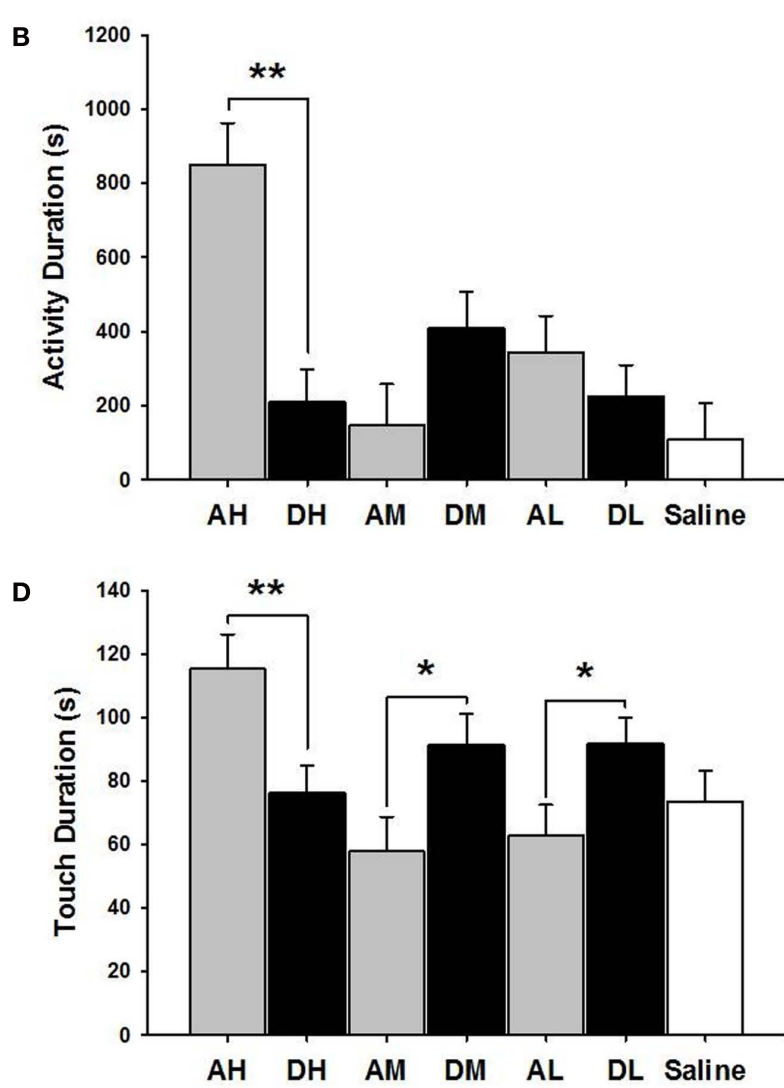

desipramine high (5 mg/kg); DM, desipramine medium ( $5 \mathrm{mg} / \mathrm{kg})$; DL, desipramine low $(1.25 \mathrm{mg} / \mathrm{kg})$ ] and saline control group in white [Saline $=$ normal saline $(2 \mathrm{ml} / \mathrm{kg})$ ]. Comparisons between amitriptyline and desipramine groups were only tested between the high, medium, or low dose groups for each respective drug treatment group. All significant $\mathrm{AH}-\mathrm{DH}, \mathrm{AM}-\mathrm{DM}$, and $\mathrm{AL}-\mathrm{DL}$ comparisons are denoted ${ }^{*} p \leq 0.05 ;{ }^{*} p \leq 0.01$.

$\left[\chi^{2}{ }_{(1)}=5.56, p \leq 0.05\right]$, medium $\left[\chi^{2}(1)=28.36, p \leq 0.01\right]$, or low $\left[\chi^{2}{ }_{(1)}=65.85, p \leq 0.01\right]$ dose desipramine groups (see Figure 4). AH dams had a higher frequency of aggressive postures compared to DH dams $\left[\chi^{2}(1)=17.58, p \leq 0.01\right]$.

\section{OXYTOCIN RADIOIMMUNOASSAY} Amitriptyline

AL dams had higher oxytocin levels in the MPOA than did saline controls $\left[\chi^{2}(1)=3.99, p \leq 0.05\right]$. AH $\left[\chi^{2}(1)=30.20, p \leq 0.01\right]$, $\mathrm{AM}\left[\chi^{2}(1)=40.15, p \leq 0.01\right]$, and $\mathrm{AL}\left[\chi^{2}(1)=46.83, p \leq 0.01\right]$ treated dams all had lower hippocampal levels of oxytocin $(\mathrm{pg} / \mathrm{mg})$ compared to saline controls (see Figure 5).

\section{Desipramine}

As seen in Figure 5, there were no significant differences between desipramine and saline control groups on levels of oxytocin in the MPOA, amygdala, or the VTA. DH treated dams had significantly lower levels of oxytocin $(\mathrm{pg} / \mathrm{mg})$ in the hippocampus compared to saline controls $\left[x^{2}{ }_{(1)}=31.43, p \leq 0.01\right]$ and significantly increased hippocampal oxytocin levels compared to DM 


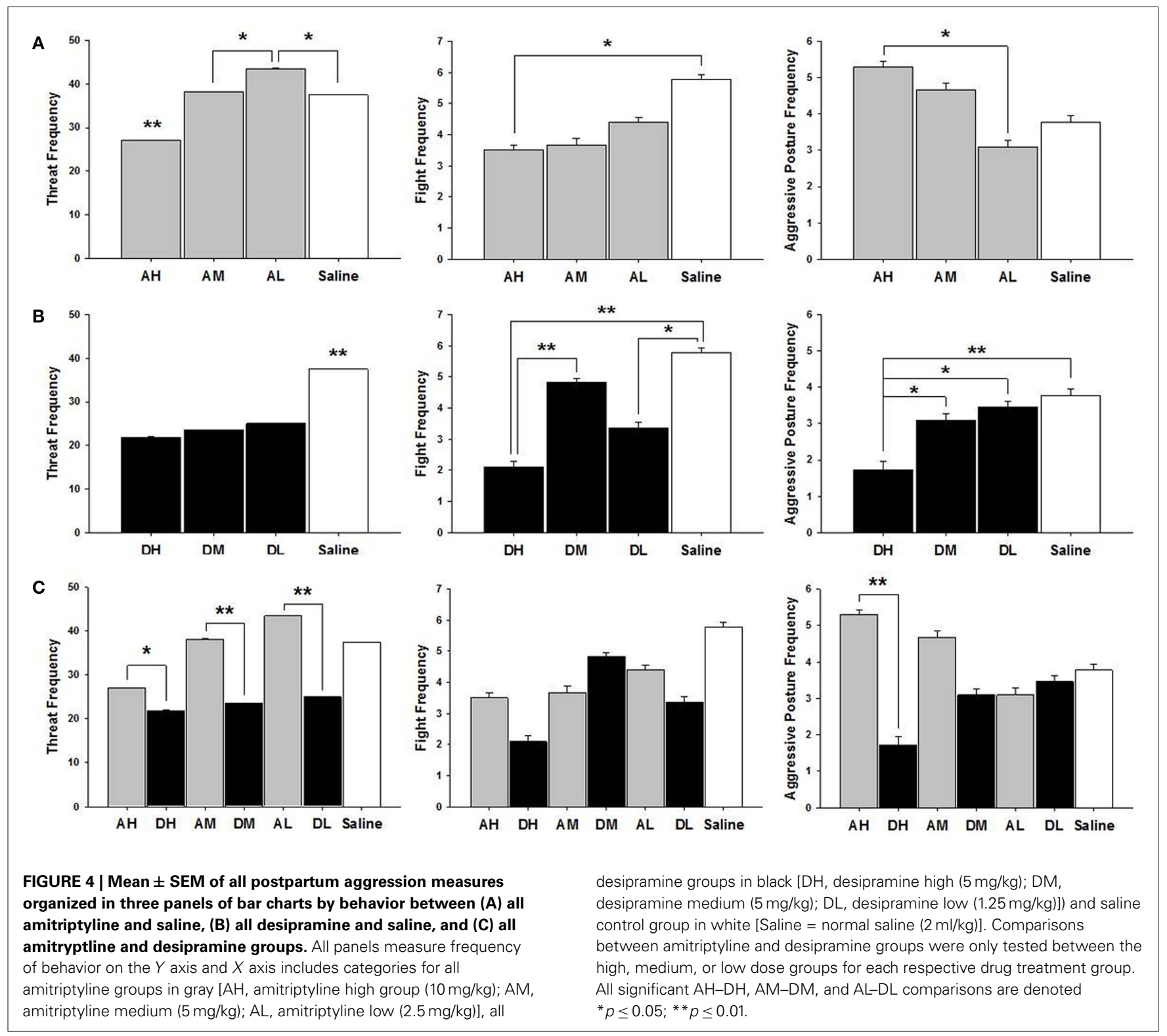

dams $\left[\chi^{2}{ }_{(1)}=7.06, p \leq 0.01\right] . \mathrm{DM}\left[\chi^{2}{ }_{(1)}=66.05, p \leq 0.01\right]$ and DL dams $\left[\chi^{2}{ }_{(1)}=50.47, p \leq 0.01\right]$ also had lower hippocampal oxytocin levels than did saline treated dams.

\section{Amitriptyline vs. desipramine}

There were no significant differences between amitriptyline and desipramine groups on oxytocin levels in any brain region tested.

\section{DISCUSSION}

We predicted that gestational desipramine treatment would have less effect on $\mathrm{MB}$ compared to amitriptyline treatment based on previous work with serotonergic reuptake inhibitors (Johns et al., 2005b). Our present data supports this hypothesis as combined 5-HT/NE reuptake inhibition resulted in greater MB alterations compared to NE reuptake inhibition alone. Chronic NE reuptake inhibition by the medium and high doses of desipramine in this study resulted in decreased crouching of dams compared to saline treated controls, and desipramine treatment was generally associated with lower levels of aggression. Results from this study support previous findings indicating a role for NE in MB. Previous studies have suggested NE plays a role in pup retrieval and disrupted nursing, as Thomas and Palmiter (1997) reported that pups born to mice lacking NE did not exhibit visible milk bands. However, the data ultimately indicated the deficits in pup feeding resulted primarily from poor maternal retrieval, resulting in a high percentage of pup litters not surviving (Thomas and Palmiter, 1997). In the present study, all dams retrieved pups with no differences in the latency to retrieve (data not shown), suggesting disruptions in crouching behavior in the desipramine treated dams were not related to retrieval. Although DM dams were more active than controls, the $\mathrm{DH}$ dams were not, so for this group at least hyperactivity did not prevent crouching. Crouching, or assuming the nursing posture, by dams is one of the most important dam 


\section{A}

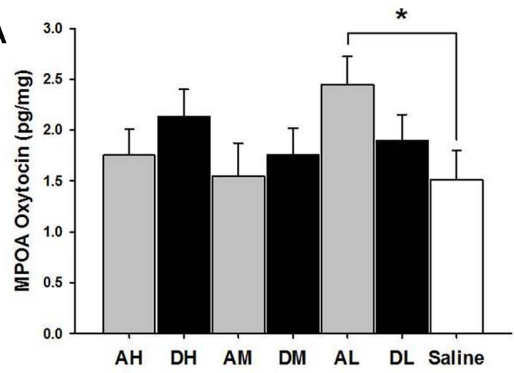

C

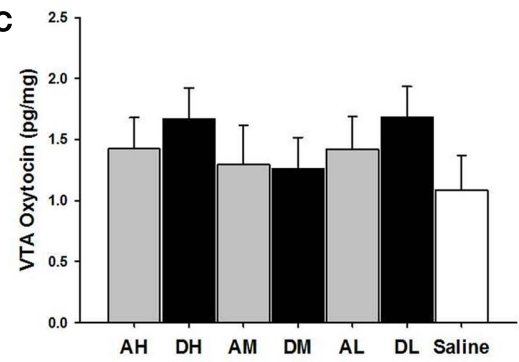

FIGURE 5 | Mean \pm SEM of all brain oxytocin measures organized in four panels of bar charts by anatomical region for all amitriptyline and desipramine groups. Each panel is for a specific anatomical region [(A) MPOA; (B) Hippocampus; (C) VTA; (D) Amygdala). All four panels measure picograms of oxytocin per milligram of brain tissue $(\mathrm{pg} / \mathrm{mg})$ on the $Y$ axis and $X$ axis includes categories for all amitriptyline groups in gray $[\mathrm{AH}$, amitriptyline high group (10 mg/kg); AM, amitriptyline medium ( $5 \mathrm{mg} / \mathrm{kg}$ ); $\mathrm{AL}$, amitriptyline
B

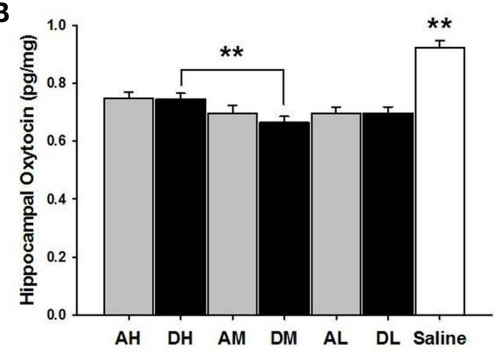

D

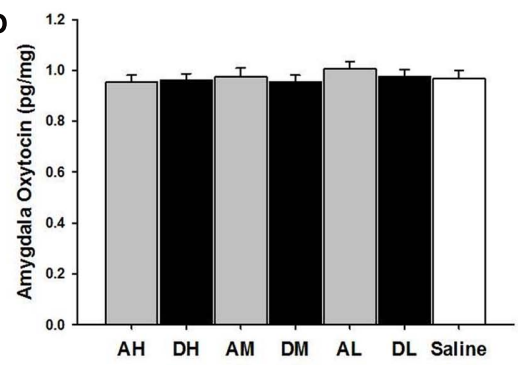

low $(2.5 \mathrm{mg} / \mathrm{kg})]$, all desipramine groups in black [DH, desipramine high $(5 \mathrm{mg} / \mathrm{kg}) ; \mathrm{DM}$, desipramine medium $(5 \mathrm{mg} / \mathrm{kg}) ; \mathrm{DL}$, desipramine low $(1.25 \mathrm{mg} / \mathrm{kg})]$ and saline control group in white [Saline $=$ normal saline $(2 \mathrm{ml} / \mathrm{kg})]$. Comparisons between amitriptyline and desipramine groups were only tested between the high, medium, or low dose groups for each respective drug treatment group. All significant $\mathrm{AH}-\mathrm{DH}, \mathrm{AM}-\mathrm{DM}$, and $\mathrm{AL}-\mathrm{DL}$ comparisons are denoted ${ }^{*} p \leq 0.05 ;{ }^{*} p \leq 0.01$. behaviors in the early postpartum period for pup survival, as they need to nurse often and starting soon after birth. Since untreated, surrogate pups were fostered to dams, we assume that pup behavior such as kneading and moving to stay under the ventrum was adequate to stimulate dams to assume the posture, and that variability in pup response would be random. NE may affect milk production by dams, and although we did not check specifically for amount of milk in dams, it is possible they could have produced somewhat less milk and thus spent less time crouching. As only the DL litters gained less weight from PPD 1-6 (see Table 2) than controls and DL dams did not differ in crouching, this argues against this interpretation. Given the evidence, we might surmise that the desipramine treatment either directly or indirectly altered this crouching behavior.

Previous studies have suggested NE may play a role in aggressive behavior of male mice, with effects dependent on the treatment and drug regimen (Matsumoto et al., 1991). Higher levels of NE have been previously associated with increased aggression in adult male human prisoners (Chichinadze et al., 2010), but few effects have been reported with respect to females in rodent or human models. In the present study, desipramine treatment decreased all aggressive behaviors measured. This is interesting as we expected no increases but did not predict significant decreases. Chronic reuptake inhibition, which would have resulted in lower levels of NE during the course of treatment, might have resulted in decreased NE levels or noradrenergic receptor binding at the time of MA testing (Bondi et al., 2007), or, alternatively, the withdrawal from desipramine may have resulted in a rebound by PPD 6 testing. Our findings support previous data suggesting NE can alter MA under some regimens, with an emphasis now on lactating females. Since we did not measure levels of NE or receptors on PPD 6, we can only speculate as to which mechanisms might be responsible for the observed behavioral effects.

While manipulations of 5-HT levels have been correlated with $\mathrm{MB}$ changes, few investigators have studied this association directly. Findings presented here suggest that combined NE and 5-HT reuptake inhibition has a greater impact on crouching compared to gestational treatment with drugs which affect either NE or 5-HT systems individually (Johns et al., 2005b). In addition, it appears more likely that activity changes may have played a role in amitriptyline related effects. Reduced crouching behavior is more of a passive behavior whereas increased touching and licking of pups seen in the high dose amitriptyline dams is more appetitive and activity specific. In light of our previous findings (Johns et al., 2005b) that chronic 5-HT reuptake inhibition (fluoxetine) alone results in strong trends for decreased crouching and increased levels of licking and touching of pups, we feel that amitriptyline's effects are very similar to fluoxetine, and somewhat different from NE reuptake inhibition alone (crouching deficits only). It seems through manipulation of the independent and combined monoamine neurotransmitter systems in this and other studies (Johns et al., 2005b), that particular behaviors may be more strongly related to specific effects of one particular monoamine neurotransmitter rather than thecombination of effects from several systems. However, it is important to note that behavioral changes observed here with the highest dose of amitriptyline, could also be related to altered DA reuptake. Although amitriptyline is relatively selective for NE and 5-HT, Di Matteo et al. (2000) 
reported an increase in DA levels in the nucleus accumbens following acute amitriptyline administration at the highest dose $(10 \mathrm{mg} / \mathrm{kg})$ used here. Gestational treatment with a low dose of a DA reuptake inhibitor also has been shown to reduce crouching, decrease latency to lick and increase pup licking and touching (Johns et al., 2005b). Future studies could examine the impact of drug dose on specific neurotransmitter system dynamics (levels, binding) to aid in interpreting pharmacological findings.

Higher 5-HT levels have been correlated with lower levels of aggression in numerous reports in rodent models, especially male rodents (Olivier and Mos, 1992; Olivier et al., 1995; Holmes et al., 2002; Miczek et al., 2007). Few reports are available for female models, particularly lactating females employing single reuptake inhibitors over gestation. Previously, we reported that dams treated chronically with fluoxetine during gestation at a high dose $(8 \mathrm{mg} / \mathrm{kg})$ resulted in dams that were less likely to nip/bite or threaten an intruder, but more likely to attack and fight them for a longer duration than controls (Johns et al., 2005b). This is interesting in light of our present findings (contrary to our predictions) that $\mathrm{AH}$ treated dams actually threatened and attacked intruders less than other amitriptyline treated and control dams. Overall, all amitriptyline treated dams threatened intruders more often compared to all desipramine treated dams, suggesting that lower levels of NE may play an inhibitory role in MA. In humans, amitriptyline has generally been found to increase aggression (Soloff et al., 1986a,b), suggesting again that the combined reuptake of 5-HT and NE might interact to offset the effect of 5-HT inhibition alone. Doses of amitriptyline and desipramine were selected to ensure minimal DA reuptake inhibition and retained selectivity for 5-HT and NE transporters; these findings are somewhat similar to the effects of combined DA and 5-HT reuptake inhibition during gestation in that the additive effect of a DA reuptake inhibitor dampens the heightened aggression following fluoxetine (Johns et al., 2005b). The doses used here do, however, have different pharmacokinetic effects on the monoamine transporters. Future studies where doses of amitriptyline and desipramine are selected to achieve different percent inhibition of 5-HT and NE transporters may produce more pronounced behavioral and neuroendocrine effects, and aid in a clearer understanding of specific neurotransmitter involvement in MBs.

We predicted oxytocin levels would be decreased in the amygdala if they were associated with increased MA following amitriptyline treatment. In light of low levels of aggression observed in both treatment groups, it is not surprising that we did not observe any oxytocin increases in the amygdala. It is plausible that the aggression levels, specifically fighting, must be significantly higher to find the related oxytocin changes we have previously seen following treatment with drugs that alter multiple reuptake inhibitor systems (Johns et al., 1994, 1998b). Decreased drug-induced aggression has been associated with increased amygdaloid oxytocin (Johns et al., 1998a) in the postpartum period after acute treatment (Johns et al., 1998a; Elliott et al., 2001) or following gestational treatment with some doses of a DA reuptake inhibitor (Johns et al., 1995). It may also be the case as we and others have suggested, and this study may indicate, that specific types of aggression may be differentially associated with oxytocin level changes in different brain regions (Caldwell et al.,
1994; Bosch et al., 2005; Consiglio et al., 2005; McMurray et al., 2008; Johns et al., 2010). Oxytocin levels were significantly lower in the hippocampus following treatment with either drug compared to saline controls, just as was the case in our earlier report using selective serotonergic and dopaminergic reuptake inhibitors (Johns et al., 2005b). The hippocampus has been more strongly associated with MB (Kimble et al., 1967) than with MA specifically in lactating models. Reduced levels (Johns et al., 1997) and receptors (Jarrett et al., 2006) for oxytocin in the early postpartum environment have been reported following treatment with cocaine, a non-selective monoaminergic reuptake inhibitor. The hippocampus is well known for its role in integration spatiotemporal memories (Hasselmo et al., 2010) and the hippocampus exhibits increased BOLD signal in response to pup suckling which can be reduced by OT antagonists (Febo et al., 2005). The entorhinal cortex, directly adjacent to the hippocampus, is involved in social memory and also exhibits the positive BOLD response to pup suckling (Febo et al., 2005). These results suggest a role for hippocampal OT sensory response to pups, perhaps encoding spatial memories of where the sensory stimulation occurred, although this has yet to be tested. Oxytocin has previously been shown to modulate neuroplasticity in the hippocampus, inducing long-term potentiation in the hippocampus of postpartum mice (Tomizawa et al., 2003) and long-term depression in male rats (Dubrovsky et al., 2002). Hippocampal oxytocin has been associated with drug dependence and tolerance (Sarnyai and Kovacs, 1994), and as such may be playing a role in the present findings. Pervasive decreases in hippocampal oxytocin with gestational administration of a wide variety of monoaminergic agents, coupled with oxytocin's known role as a modulator of hippocampal synaptic strength and potential role in social recognition and perception (Cole and Young, 2009; Theodoridou et al., 2009), warrant future studies assessing the role of monoaminergic reuptake inhibitors on hippocampal neuroplasticity in the maternal brain.

The present study was not without limitations, including no direct assessment of changes in NE, 5-HT, and DA levels or receptors in brain regions of interest following drug treatment. Our focus on the oxytocin system prevented these measurements of monoamine system function in a single cohort of animals. The use of only male surrogate pups results in a loss of generalizability of the effects to a larger population, although previous studies have shown drug-induced effects with mixed litters as well (Johns et al., 2005a). The drugs chosen for this study were not the most selective available for the respective neurotransmitter systems, but in some respects quite relevant considering treatment for serotonin selective reuptake inhibitor refractory depression employs the use of combined NE/5-HT neurotransmitter uptake inhibitors like amitriptyline and desipramine. However, as observed here, particular dose pharmacokinetics need to be further explored, as low and medium doses of amitriptyline had little effect on $\mathrm{MB}$, and drug dose-behavior relationship studies aimed atunderstanding complex mechanisms driving behavioral changes could be of clinical relevance.

While we did not assess changes in anxiety and stress in this particular study, both have been correlated with deficits in maternal care (Smith et al., 2004; Bosch et al., 2007; Chen et al., 2010; Kessler et al., 2011). To the extent that dams in this study may have been 
experiencing some effects of drug withdrawal at time of testing (none were noted), it is important to acknowledge that this could have had some effects on the behaviors measured here. We did not detect any problems with lesions or distress following either drug administration. While the $\mathrm{AH}$ dams did gain less gestational weight they did not suffer notable sudden weight loss. Milk production did not seem to be restricted in $\mathrm{AH}$ dams as all pups nursed and had milk bands. These animals were more active and perhaps there were some anorectic effects as were evident in a previous fluoxetine study at the high dose level (Johns et al., 2005b) which could have had some effects on behaviors measured. It is also important to remember that effects of drugs used as antidepressants in an animal model must be carefully interpreted, as this model does not have an overt depressive-like phenotype (Pollak et al., 2010), and as such, may not reflect the pharmacological effects these compounds would have in depressed or drug abusing human mothers. Future studies like this one using an animal model of depression might prove interesting. In conclusion, given the high rates women use legal and illicit monoamine reuptake

\section{REFERENCES}

Bagdy, G., and Kalogeras, K. T. (1993). Stimulation of 5-HT1A and 5HT2/5-HT1C receptors induce oxytocin release in the male rat. Brain Res. 611, 330-332.

Bagdy, G., Kalogeras, K. T., and Szemeredi, K. (1992). Effect of 5HT1C and 5-HT2 receptor stimulation on excessive grooming, penile erection and plasma oxytocin concentrations. Eur. J. Pharmacol. 229, 9-14.

Bealer, S. L., and Flynn, F. W. (2003). Central neurokinin 3 receptors increase systemic oxytocin release: interaction with norepinephrine. Exp. Neurol. 184, 1027-1033.

Benjamini, Y., Drai, D., Elmer, G., Kafkafi, N., and Golani, I. (2001). Controlling the false discovery rate in behavior genetics research. Behav. Brain Res. 125, 279-284.

Benmansour, S., Cecchi, M., Morilak, D. A., Gerhardt, G. A., Javors, M. A., Gould, G. G., and Frazer, A. (1999). Effects of chronic antidepressant treatments on serotonin transporter function, density, and mRNA level. J. Neurosci. 19, 10494-10501.

Bennett, H. A., Einarson, A., Taddio, A., Koren, G., and Einarson, T. R. (2004). Prevalence of depression during pregnancy: systematic review. Obstet. Gynecol. 103, 698-709.

Bolden-Watson, C., and Richelson, E. (1993). Blockade by newlydeveloped antidepressants of biogenic amine uptake into rat brain synaptosomes. Life Sci. 52, 1023-1029.

Bondi, C. O., Barrera, G., Lapiz, M. D., Bedard, T., Mahan, A., and Morilak,
D. A. (2007). Noradrenergic facilitation of shock-probe defensive burying in lateral septum of rats, and with desipramine. Prog. Neuropsychopharmacol. Biol. Psychiatry 31, 482-495.

Bosch, O. J., Meddle, S. L., Beiderbeck, D. I., Douglas, A. J., and Neumann, I. D. (2005). Brain oxytocin correlates with maternal aggression: link to anxiety. J. Neurosci. 25, 6807-6815.

Bosch, O. J., Musch, W., Bredewold, R., Slattery, D. A., and Neumann, I. D. (2007). Prenatal stress increases HPA axis activity and impairs maternal care in lactating female offspring: implications for postpartum mood disorder. Psychoneuroendocrinology 32, 267-278.

Brodin, K., Ogren, S. O., and Brodin, E. (1994). Clomipramine and clonazepam increase cholecystokinin levels in rat ventral tegmental area and limbic regions. Eur. J. Pharmacol. 263, 175-180.

Caldwell, J. D., Johns, J. M., FagPedersen, C. A. (1994). Infusion of an oxytocin antagonist into the medial preoptic area prior to progesterone inhibits sexual receptivity and increases rejection in female rats. Horm. Behav. 28, 288-302.

Chen, Y., Holzman, C., Chung, H., Senagore, P., Talge, N. M., and SilerKhodr, T. (2010). Levels of maternal serum corticotropin-releasing hormone $(\mathrm{CRH})$ at midpregnancy in relation to maternal characteristics. Psychoneuroendocrinology 35, 820-832. modulation by chronic treatment gin, B. M., Senger, M. A., and

inhibitors, further exploration of these models could prove useful for studying how the action of these drugs may alter the dynamics of the mother-infant relationship. This study, in combination with other previous reports, highlights the complexity and importance of understanding the biological underpinnings of maternal care.

\section{ACKNOWLEDGMENTS}

We would like to acknowledge our pharmacology consultant Dr. Brian McMillen. This project was supported by NIH grants DA R0113283 and P01 DA022446 (Josephine M. Johns). Elizabeth Thomas Cox was supported in part by NIDA pre-doctoral training grant (F31 DA030060). Matthew Stephen McMurray was supported in part by NIDA pre-doctoral training grant (F31 DA026251). Thomas Merryfield Jarrett was supported while working on this project by Award Number TLRR025745 from the National Center for Research Resources as a pre-doctoral trainee. The content is solely the responsibility of the authors and does not necessarily represent the official views of the National Center for Research Resources or the National Institutes of Health.

Chichinadze, K. N., Domianidze, T. R., Matitaishvili, T. T., Chichinadze, N. K., and Lazarashvili, A. G. (2010). Possible relation of plasma testosterone level to aggressive behavior of male prisoners. Bull. Exp. Biol. Med. 149, 7-9.

Coccaro, E. F., and Kavoussi, R. J. (1997). Fluoxetine and impulsive aggressive behavior in personality-disordered subjects. Arch. Gen. Psychiatry 54, 1081-1088.

Coccaro, E. F., Kavoussi, R. J., and Hauger, R. L. (1997). Serotonin function and antiaggressive response to fluoxetine: a pilot study. Biol. Psychiatry 42, 546-552.

Cole, C. D., and Young, L. J. (2009). "Neuroendocrinology of social affiliative behavior," in Encyclopedia of Neuroscience, ed. L. R. Squire (Burlington, MA: Elsevier), 377-383.

Consiglio, A. R., Borsoi, A., Pereira, G. A., and Lucion, A. B. (2005). Effects of oxytocin microinjected into the central amygdaloid nucleus and bed nucleus of stria terminalis on maternal aggressive behavior in rats. Physiol. Behav. 85, 354-362.

Cooper, J. R., Bloom, F. E., and Roth, R. H. (1996). The Biological Basis of Neuropharmacology. New York: Oxford University Press.

Cooper, W. O., Willy, M. E., Pont, S. J., and Ray, W. A. (2007). Increasing use of antidepressants in pregnancy. Am. J. Obstet. Gynecol. 196, 544-545.

Cummings, J. A., Clemens, L. G., and Nunez, A. A. (2010). Mother counts: how effects of environmental contaminants on maternal care could affect the offspring and future generations. Front. Neuroendocrinol. 31:4. doi: 10.1016/j.yfrne.2010.05.004

Di Matteo, V., Di Mascio, M., Di Giovanni, G., and Esposito, E. (2000). Acute administration of amitriptyline and mianserin increases dopamine release in the rat nucleus accumbens: possible involvement of serotonin2C receptors. Psychopharmacology (Berl.) 150, 45-51.

Dubrovsky, B., Harris, J., Gijsbers, K., and Tatarinov, A. (2002). Oxytocin induces long-term depression on the rat dentate gyrus: possible ATPase and ectoprotein kinase mediation. Brain Res. Bull. 58, 141-147.

Elliott, J. C., Lubin, D. A., Walker, C. H., and Johns, J. M. (2001). Acute cocaine alters oxytocin levels in the medial preoptic area and amygdala in lactating rat dams: implications for cocaine-induced changes in maternal behavior and maternal aggression. Neuropeptides 35, 127-134.

Febo, M., Numan, M., and Ferris, C. F. (2005). Functional magnetic resonance imaging shows oxytocin activates brain regions associated with mother-pup bonding during suckling. J. Neurosci. 25, 11637-11644.

Feldman, R., Weller, A., ZagoorySharon, O., and Levine, A. (2007). Evidence for a neuroendocrinological foundation of human affiliation: plasma oxytocin levels across pregnancy and the postpartum period predict mother-infant bonding. Psychol. Sci. 18, 965-970. 
Ferris, C. F., Foote, K. B., Meltser, H. M., Plenby, M. G., Smith, K. L., and Insel, T. R. (1992). "Oxytocin in the amygdala facilitates maternal aggression," in Oxytocin in Maternal, Sexual, and Social Behaviors, eds C. A. Pedersen, J. D. Caldwell, G. F. Jirikowski, and T. R. Insel (New York: The New York Academy of Sciences), 456-457.

Ferro, T., Verdeli, H., Pierre, F., and Weissman, M. M. (2000). Screening for depression in mothers bringing their offspring for evaluation or treatment of depression. Am. J. Psychiatry 157, 375-379.

Gaynes, B. N., Gavin, N., MeltzerBrody, S., Lohr, K. N., Swinson, T., Gartlehner, G., Brody, S., and Miller, W. C. (2005). Perinatal depression: prevalence, screening accuracy, and screening outcomes. Evid. Rep. Technol. Assess. (Summ.) 119, 1-8.

Ghose, K. (1980). Decreased tyramine sensitivity after discontinuation of amitriptyline therapy. An index of pharmacodynamic half-life. Eur. J. Clin. Pharmacol. 18, 151-117.

Goldberg, H., and Nissim, R. (1994). Psychotropic drugs in pregnancy and lactation. Int. J. Psychiatry Med. 24, 129-149.

Gore, A. C. (2001). Environmental toxicant effects on neuroendocrine function. Endocrine 14, 235-246.

Gould, G. G., Altamirano, A. V., Javors, M. A., and Frazer, A. (2006). A comparison of the chronic treatment effects of venlafaxine and other antidepressants on serotonin and norepinephrine transporters. Biol. Psychiatry 59, 408-414.

Grover, S., Avasthi, A., and Sharma, Y. (2006). Psychotropics in pregnancy: weighing the risks. Indian J. Med. Res. 123, 497-512.

Hahn, M. E., and Lavooy, M. J. (2005). A review of the methods of studies on infant ultrasound production and maternal retrieval in small rodents. Behav. Genet. 35, 31-52.

Hasselmo, M. E., Giocomo, L. M., Brandon, M. P., and Yoshida, M. (2010). Cellular dynamical mechanisms for encoding the time and place of events along spatiotemporal trajectories in episodic memory. Behav. Brain Res. 215, 261-274.

Henderson, M. G., and McMillen, B. A. (1993). Changes in dopamine, serotonin and their metabolites in discrete brain areas of rat offspring after in utero exposure to cocaine or related drugs. Teratology $48,421-430$

Holmes, A., Murphy, D. L., and Crawley, J. N. (2002). Reduced aggression in mice lacking the serotonin transporter. Psychopharmacology (Berl.) 161, 160-167.
Jarrett, T. M., McMurray, M. S., Walker, C. H., and Johns, J. M. (2006). Cocaine treatment alters oxytocin receptor binding but not mRNA production in postpartum rat dams. Neuropeptides 40, 161-167.

Johns, J. M., Elliott, D. L., Hofler, V. E., Joyner, P. W., McMurray, M. S. Jarrett, T. M., Haslup, A. M., Middleton, C. L., Elliott, J. C., and Walker, C. H. (2005a). Cocaine treatment and prenatal environment interact to disrupt intergenerational maternal behavior in rats. Behav. Neurosci. 119, 1605-1618.

Johns, J. M., Joyner, P. W., McMurray, M. S., Elliott, D. L., Hofler, V. E., Middleton, C. L., Knupp, K., Greenhill, K. W., Lomas, L. M., and Walker, C. H. (2005b). The effects of dopaminergic/serotonergic reuptake inhibition on maternal behavior, maternal aggression, and oxytocin in the rat. Pharmacol. Biochem. Behav. 81, 769-785.

Johns, J. M., Faggin, B. M., Noonan, L. R., Li, L., Zimmerman, L. I., and Pedersen, C. A. (1995). Chronic cocaine treatment decreases oxytocin levels in the amygdala and increases maternal aggression in Sprague-Dawley rats. Soc. Neurosci. Abstr. 21, 766.7.

Johns, J. M., Lubin, D. A., Walker, C. H., Joyner, P., Middleton, C., Hofler, V., and McMurray, M. (2004). Gestational treatment with cocaine and fluoxetine alters oxytocin receptor number and binding affinity in lactating rat dams. Int. J. Dev. Neurosci. $22,321-328$.

Johns, J. M., Lubin, D. A., Walker, C. H., Meter, K. E., and Mason, G. A. (1997). Chronic gestational cocaine treatment decreases oxytocin levels in the medial preoptic area, ventral tegmental area and hippocampus in Sprague-Dawley rats. Neuropeptides $31,439-443$

Johns, J. M., McMurray, M. S., Joyner, P. W., Jarrett, T. M., Williams, S. K., Cox, E. T., Black, M. A., Middleton, C. L., and Walker, C. H. (2010). Effects of chronic and intermittent cocaine treatment on dominance, aggression, and oxytocin levels in post-lactational rats. Psychopharmacology (Berl.) 211, 175-185.

Johns, J. M., Nelson, C. J., Meter, K. E., Lubin, D. A., Couch, C. D., Ayers, A., and Walker, C. H. (1998a). Dose-dependent effects of multiple acute cocaine injections on maternal behavior and aggression in Sprague-Dawley rats. Dev. Neurosci. 20, 525-532.

Johns, J. M., Noonan, L. R., Zimmerman, L. I., McMillen, B. A., Means, L. W., Walker, C. H., Lubin, D. A. Meter, K. E., Nelson, C. J., Pedersen,
C. A., Mason, G. A., and Lauder, J. M. (1998b). Chronic cocaine treatment alters social/aggressive behavior in Sprague-Dawley rat dams and in their prenatally exposed offspring. Ann. N. Y. Acad. Sci. 846, 399-404.

Johns, J. M., Noonan, L. R., Zimmerman, L. I., Li, L., and Pedersen, C. A. (1994). Effects of chronic and acute cocaine treatment on the onset of maternal behavior and aggression in Sprague-Dawley rats. Behav Neurosci. 108, 107-112.

Jorgensen, H., Kjaer, A., Knigge, U., Moller, M., and Warberg, J. (2003). Serotonin stimulates hypothalamic mRNA expression and local release of neurohypophysial peptides. $J$. Neuroendocrinol. 15, 564-571.

Jorgensen, H., Knigge, U., Kjaer, A., and Warberg, J. (2002). Serotonergic involvement in stress-induced vasopressin and oxytocin secretion. Eur. J. Endocrinol. 147, 815-824.

Keer, S. E., and Stern, J. M. (1999). Dopamine receptor blockade in the nucleus accumbens inhibits maternal retrieval and licking, but enhances nursing behavior in lactating rats. Physiol. Behav. 67, 659-669.

Kessler, M. S., Bosch, O. J., Bunck, M., Landgraf, R., and Neumann, I. D. (2011). Maternal care differs in mice bred for high vs. low trait anxiety: impact of brain vasopressin and cross-fostering. Soc.Neurosci. 6 156-168.

Kessler, R. C., McGonagle, K. A., Swartz, M., Blazer, D. G., and Nelson, C. B. (1993). Sex and depression in the National Comorbidity Survey. I: lifetime prevalence, chronicity and recurrence. J. Affect. Disord. 29, 85-96.

Kessler, R. C., McGonagle, K. A., Zhao, S., Nelson, C. B., Hughes, M., Eshleman, S., Wittchen, H. U., and Kendler, K. S. (1994). Lifetime and 12-month prevalence of DSM-III-R psychiatric disorders in the United States. Results from the National Comorbidity Survey. Arch. Gen. Psychiatry 51, 8-19.

Kimble, D. P., Rogers, L., and Hendrickson, C. W. (1967). Hippocampal lesions disrupt maternal, not sexual behavior in the albino rat. $J$. Comp. Physiol. Psychol. 63, 401-407.

Konig, J. F. R., and Klippel, R. A. (1963) The Rat Brain: A Stereotaxic Atlas of the Forebrain and Lower Parts of the Brain Stem. New York: Krieger.

Lerch-Haner, J. K., Frierson, D., Crawford, L. K., Beck, S. G., and Deneris, E. S. (2008). Serotonergic transcriptional programming determines maternal behavior and offspring survival. Nat. Neurosci. 11 1001-1003.
Levine, A., Zagoory-Sharon, O., Feldman, R., and Weller, A. (2007). Oxytocin during pregnancy and early postpartum: individual patterns and maternal-fetal attachment. Peptides 28, 1162-1169.

Lipschitz, D. L., Crowley, W. R., and Bealer, S. L. (2004). Differential sensitivity of intranuclear and systemic oxytocin release to central noradrenergic receptor stimulation during mid- and late gestation in rats. $A m$. J. Physiol. Endocrinol. Metab 287, E523-E528.

Logsdon, M. C., Wisner, K., and Hanusa, B. H. (2009). Does maternal role functioning improve with antidepressant treatment in women with postpartum depression? J. Womens Health (Larchmt.) 18, 85-90.

Lonstein, J. S., and Gammie, S. C. (2002). Sensory, hormonal, and neural control of maternal aggression in laboratory rodents. Neurosci. Biobehav. Rev. 26, 869-888.

Lubin, D. A., Elliott, J. C., Black, M. C., and Johns, J. M. (2003) An oxytocin antagonist infused into the central nucleus of the amygdala increases maternal aggressive behavior. Behav. Neurosci. 117, 195-201.

Marek, G. J., Li, A., and Seiden, L. S. (1988). Antidepressant-like effects of (+)-oxaprotiline on a behavioral screen. Eur. J. Pharmacol. 157, 183-188.

Matsumoto, K., Cai, B., Satoh, T. Ohta, H., and Watanabe, H. (1991) Desipramine enhances isolationinduced aggressive behavior in mice Pharmacol. Biochem. Behav. 39, 167-170.

Matsumoto, K., Ojima, K., and Watanabe, H. (1995). Noradrenergic denervation attenuates desipramine enhancement of aggressive behavior in isolated mice. Pharmacol Biochem. Behav. 50, 481-484.

Mayer, A. D., and Rosenblatt, J. S. (1998). A method for regulating the duration of pregnancy and the time of parturition in Sprague-Dawley rats (Charles River CD strain). Dev. Psychobiol. 32, 131-136.

McMurray, M. S., Joyner, P. W., Middleton, C. W., Jarrett, T. M., Elliott, D. L., Black, M. A., Hofler, V. E., Walker, C. H., and Johns, J. M. (2008). Intergenerational effects of cocaine on maternal aggressive behavior and brain oxytocin in rat dams. Stress 11, 398-410.

Miczek, K. A., De Almeida, R. M., Kravitz, E. A., Rissman, E. F., de Boer, S. F., and Raine, A. (2007). Neurobiology of escalated aggression and violence. J. Neurosci. 27 11803-11806. 
Montero, D., de Ceballos, M. L., and Del Rio, J. (1990). Down-regulation of $3 \mathrm{H}$-imipramine binding sites in cerebral cortex after prenatal exposure to antidepressants. Life Sci. 46, 1619-1626.

Neumann, I. D. (2008). Brain oxytocin: a key regulator of emotional and social behaviours in both females and males. J. Neuroendocrinol. 20, 858-865.

Neumann, I. D. (2009). The advantage of social living: brain neuropeptides mediate the beneficial consequences of sex and motherhood. Front. Neuroendocrinol. 30:4. doi: 10.1016/j.yfrne.2009.04.012

Nicholson, G. M., Blanche, T., Mansfield, K., and Tran, Y. (2002). Differential blockade of neuronal voltagegated $\mathrm{Na}(+)$ and $\mathrm{K}(+)$ channels by antidepressant drugs. Eur. J. Pharmacol. 452, 35-48.

Nissen, E., Gustavsson, P., Widstrom, A. M., and Uvnas-Moberg, K. (1998). Oxytocin, prolactin, milk production and their relationship with personality traits in women after vaginal delivery or Cesarean section. J. Psychosom. Obstet. Gynaecol. 19, 49-58.

Olivier, B., and Mos, J. (1992). Rodent models of aggressive behavior and serotonergic drugs. Prog. Neuropsychopharmacol. Biol. Psychiatry 16, 847-870.

Olivier, B., Mos, J., van Oorschot, R., and Hen, R. (1995). Serotonin receptors and animal models of aggressive behavior. Pharmacopsychiatry 28, 80-89.

Pedersen, C. A., Caldwell, J. D., Walker, C., Ayers, G., and Mason, G. A. (1994). Oxytocin activates the postpartum onset of rat maternal behavior in the ventral tegmental and medial preoptic areas. Behav. Neurosci. 108, 1163-1171.

Pollak, D. D., Rey, C. E., and Monje, F. J. (2010). Rodent models in depression research: classical strategies and new directions. Ann. Med. 42, 252-264.
Porrino, L. J., Ritz, M. C., Goodman, N. L., Sharpe, L. G., Kuhar, M. J., and Goldberg, S. R. (1989). Differential effects of the pharmacological manipulation of serotonin systems on cocaine and amphetamine selfadministration in rats. Life Sci. 45, 1529-1535.

Ritz, M. C., Cone, E. J., and Kuhar, M. J. (1990). Cocaine inhibition of ligand binding at dopamine, norepinephrine and serotonin transporters: a structure-activity study. Life Sci. 46, 635-645.

Rosenberg, P., Halaris, A., and Moltz, H. (1977). Effects of central norepinephrine depletion on the initiation and maintenance of maternal behavior in the rat. Pharmacol. Biochem. Behav. 6, 21-24.

Russell, J. A., Leng, G., and Douglas, A. J. (2003). The magnocellular oxytocin system, the fount of maternity: adaptations in pregnancy. Front. Neuroendocrinol. 24:1. doi: 10.1016/S0091-3022(02)00104-8

Sallee, F. R., and Pollock, B. G. (1990). Clinical pharmacokinetics of imipramine and desipramine. Clin. Pharmacokinet. 18, 346-364.

Sarnyai, Z., and Kovacs, G. L. (1994). Role of oxytocin in the neuroadaptation to drugs of abuse. Psychoneuroendocrinology 19, 85-117.

Sawchenko, P. E., Swanson, L. W., Steinbusch, H. W., and Verhofstad, A. A. (1983). The distribution and cells of origin of serotonergic inputs to the paraventricular and supraoptic nuclei of the rat. Brain Res. 277, 355-360.

Saydoff, J. A., Rittenhouse, P. A., Van De Kar, L. D., and Brownfield, M. S. (1991). Enhanced seotonergic transmission stimulates oxytocin secretion in conscious male rats. J. Pharmacol. Exp. Ther. 257, 95-99.

Schatzberg, A. F. (1998). Noradrenergic versus serotonergic antidepressants: predictors of treatment response. J. Clin. Psychiatry 59(Suppl. 14), 15-18.
Scholtens, J., Roozen, M., Mirmiran, M., and van de Poll, N. E. (1990). Role of noradrenaline in behavioral changes after defeat in male and female rats. Behav. Brain Res. 36, 199-202.

Schulz, P., Dick, P., Blaschke, T. F., and Hollister, L. (1985). Discrepancies between pharmacokinetic studies of amitriptyline. Clin. Pharmacokinet. $10,257-268$.

Smith, J. W., Seckl, J. R., Evans, A. T., Costall, B., and Smythe, J. W. (2004). Gestational stress induces post-partum depression-like behaviour and alters maternal care in rats. Psychoneuroendocrinology 29 227-244.

Soloff, P. H., George, A., Nathan R. S., Schulz, P. M., and Perel, J. M. (1986a). Paradoxical effects of amitriptyline on borderline patients. Am. J. Psychiatry 143, 1603-1605.

Soloff, P. H., George, A., Nathan, S., Schulz, P. M., Ulrich, R. F., and Perel, J. M. (1986b). Amitriptyline and haloperidol in unstable and schizotypal borderline disorders. Psychopharmacol. Bull. 22, 177-182.

Sorensen, D. B., Johnsen, P. F., Bibby, B. M., Bottner, A., Bornstein, S R., Eisenhofer, G., Pacak, K., and Hansen, A. K. (2005). PNMT transgenic mice have an aggressive phenotype. Horm. Metab Res. 37, 159-163.

Strathearn, L., and Mayes, L. C. (2010). Cocaine addiction in mothers: potential effects on maternal care and infant development. Ann. N. Y. Acad. Sci. 1187, 172-183.

Theodoridou, A., Rowe, A. C., PentonVoak, I. S., and Rogers, P. J. (2009). Oxytocin and social perception: oxytocin increases perceived facial trustworthiness and attractiveness. Horm. Behav. 56, 128-132.

Thomas, S. A., and Palmiter, R. D. (1997). Impaired maternal behavior in mice lacking norepinephrine and epinephrine. Cell 91, 583-592.
Tomizawa, K., Iga, N., Lu, Y. F., Moriwaki, A., Matsushita, M., Li, S. T. Miyamoto, O., Itano, T., and Matsui, H. (2003). Oxytocin improves long-lasting spatial memory during motherhood through MAP kinase cascade. Nat. Neurosci. 6, 384-390.

Uvnas-Moberg, K., Hillegaart, V., Alster, P., and Ahlenius, S. (1996). Effects of 5-HT agonists, selective for different receptor subtypes, on oxytocin, CCK, gastrin and somatostatin plasma levels in the rat. $\mathrm{Neu}$ ropharmacology 35, 1635-1640.

Weissman, M. M., Warner, V., Wickramaratne, P., and Prusoff, B. A (1988). Early-onset major depression in parents and their children. J. Affect. Disord. 15, 269-277.

Conflict of Interest Statement: The authors declare that the research was conducted in the absence of any commercial or financial relationships that could be construed as a potential conflict of interest.

Received: 18 February 2011; accepted: 26 May 2011; published online: 08 June 2011.

Citation: Cox ET, Jarrett TM, McMurray MS, Greenhill K, Hofler VE, Williams SK, Joyner PW, Middleton CL, Walker $\mathrm{CH}$ and Johns JM (2011) Combined norepinephrine/serotonergic reuptake inhibition: effects on maternal behavior, aggression, and oxytocin in the rat. Front. Psychiatry 2:34. doi: 10.3389/fpsyt.2011.00034

This article was submitted to Frontiers in Child and Neurodevelopmental Psychiatry, a specialty of Frontiers in Psychiatry. Copyright (c) 2011 Cox, Jarrett, McMurray, Greenhill, Hofler, Williams, Joyner, Middleton, Walker and Johns. This is an open-access article subject to a non-exclusive license between the authors and Frontiers Media SA, which permits use, distribution and reproduction in other forums, provided the original authors and source are credited and other Frontiers conditions are complied with. 